\title{
Industrial biotechnology of Pseudomonas putida: advances and prospects
}

\author{
Anna Weimer ${ }^{1} \cdot$ Michael Kohlstedt $^{1} \cdot$ Daniel C. Volke ${ }^{2} \cdot$ Pablo I. Nikel $^{2} \cdot$ Christoph Wittmann $^{1}$ (D)
}

Received: 24 June 2020 / Revised: 23 July 2020 / Accepted: 2 August 2020 / Published online: 13 August 2020

(C) The Author(s) 2020

\begin{abstract}
Pseudomonas putida is a Gram-negative, rod-shaped bacterium that can be encountered in diverse ecological habitats. This ubiquity is traced to its remarkably versatile metabolism, adapted to withstand physicochemical stress, and the capacity to thrive in harsh environments. Owing to these characteristics, there is a growing interest in this microbe for industrial use, and the corresponding research has made rapid progress in recent years. Hereby, strong drivers are the exploitation of cheap renewable feedstocks and waste streams to produce value-added chemicals and the steady progress in genetic strain engineering and systems biology understanding of this bacterium. Here, we summarize the recent advances and prospects in genetic engineering, systems and synthetic biology, and applications of $P$. putida as a cell factory.
\end{abstract}

\section{Key points}

- Pseudomonas putida advances to a global industrial cell factory.

- Novel tools enable system-wide understanding and streamlined genomic engineering.

- Applications of P. putida range from bioeconomy chemicals to biosynthetic drugs.

Keywords Pseudomonas putida - Microbial cell factory - KT2440 - EDEMP cycle - Bacterial chassis · Biocatalysis . Biotransformation $\cdot$ Metabolic engineering $\cdot$ Synthetic biology $\cdot$ Bioeconomy $\cdot$ Lignin $\cdot$ PHA

\section{Introduction}

Pseudomonas putida is a Gram-negative, rod-shaped bacterium, frequently isolated from waters, plants, and soils (in particular, polluted sites) (Fig. 1). The heterogeneity of P. putida's natural environment is reflected by its opportunistic and undemanding nutritional capabilities, rapid growth, as well as robustness upon challenges with oxidative stress and toxic chemicals. Initiated by the discovery of the potential of P. putida in biodegradation of xenobiotics in the 1960 s (Nakazawa 2002), the acquisition of knowledge about the

Electronic supplementary material The online version of this article (https://doi.org/10.1007/s00253-020-10811-9) contains supplementary material, which is available to authorized users.

Christoph Wittmann

christoph.wittmann@uni-saarland.de

1 Institute of Systems Biotechnology, Saarland University, Campus A1.5, 66123 Saarbrücken, Germany

2 The Novo Nordisk Foundation Center for Biosustainability, Technical University of Denmark, Lyngby, Denmark genetics, biochemistry, and physiology of this microbe has been continuously progressing over the last five decades. This led, inter alia, to the decryption of the complete genomic repertoire (Belda et al. 2016; Nelson et al. 2002) (Fig. 2) and the construction of genome-scale metabolic models for in silico simulations and data mapping (Nogales et al. 2020; Puchałka et al. 2008). Moreover, an ever growing number of tools for systems-level profiling, targeted genetic and genome manipulations are being developed (Cook et al. 2018; Martínez-García and de Lorenzo 2017). This increasing knowledge and technology, together with the intrinsic biochemical capabilities of the bacterium, offers vast industrial application potential. Among others, representative members of the species have been identified as plant growth-promoting microbes (Glick 2012), bioremediation agents (Dvořák et al. 2017), and hosts for industrial bio-manufacturing, including the production of bulk and specialty chemicals (Nikel and de Lorenzo 2018; Poblete-Castro et al. 2012a; Tiso et al. 2014), natural products, such as rhamnolipids, terpenoids, polyketides and non-ribosomal peptides (Loeschcke and Thies 2015), and biopolymers (Mozejko-Ciesielska et al. 2019; Rehm and Valla 1997; Salvachúa et al. 2020a). The 
Fig. 1. Isolation, source, and distribution of $P$. putida strains with full genome sequence available. The $P$. putida strains have been isolated from soil, polluted soil, water, polluted water, and/or wastewater and other unspecified sources (Data from Pseudomonas Genome DB and NCBI BioSamples Database, accessed: 05/20/2020; see Tables S2 for further information.)

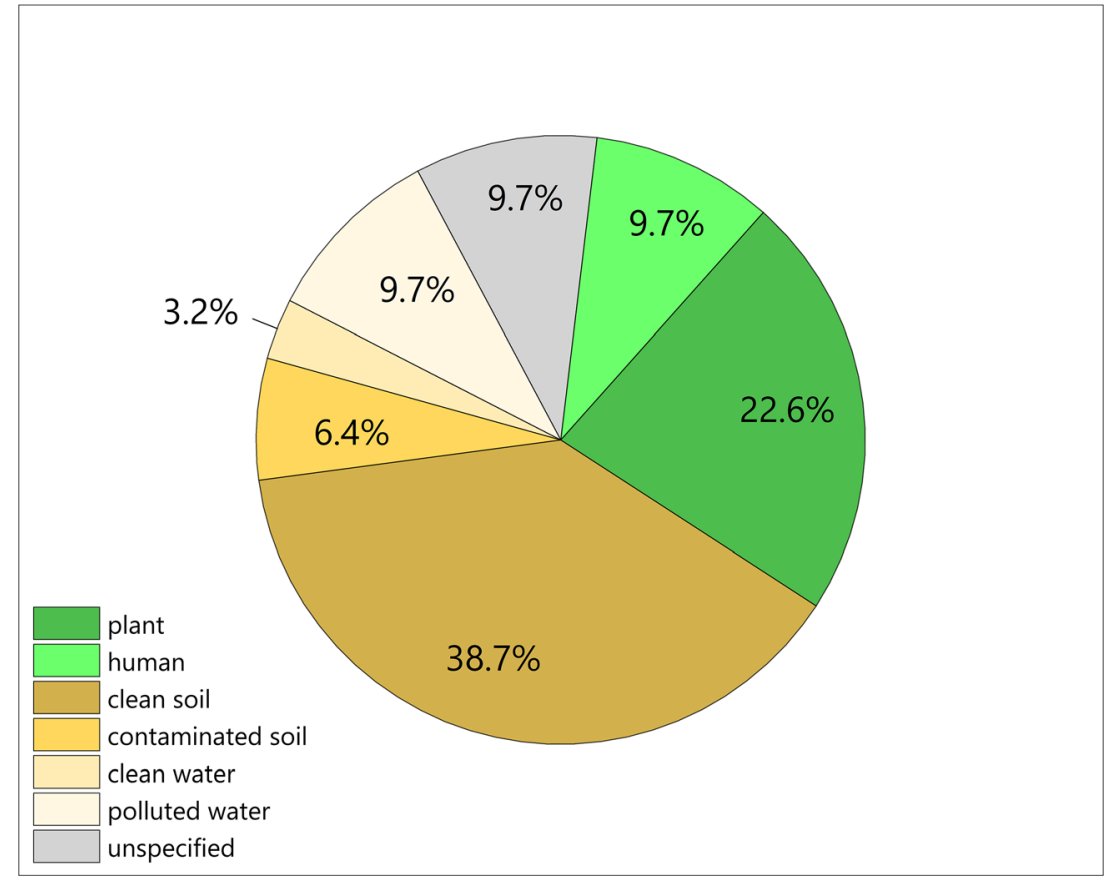

most prominent and well-studied TOL plasmid-free strain $P$. putida KT2440 has been especially considered as a microbial host for biotechnological application, due to its biosafety status (National Archives and Records Administration 1982). Other strains for industrial use include the solvent-tolerant strains $P$. putida S12, DOT-T1E, and VLB120 (Kohler et al. 2013; Udaondo et al. 2012; Wierckx et al. 2005), the plant growth-promoting strains BIRD-1 and UW4 (Duan et al. 2013; Matilla and Krell 2018), the phenol-degrading H strain (Müller et al. 1996), strain LS46 for production of mediumchain-length polyhydroxyalkanoates (mcl-PHA) (Sharma et al. 2014), as well as P. putida F1, isolated from soil and developed into a bioremediation agent (Choi et al. 2003). Over the past years, research on $P$. putida has immensely progressed. Recent prominent innovations include highresolution metabolic flux analysis (Kohlstedt and Wittmann 2019; Nikel et al. 2015; Sasnow et al. 2016), synthetic remodeling of the metabolic core machinery (Sánchez-Pascuala et al. 2019), production of green chemicals from lignin feedstocks (Kohlstedt et al. 2018; Salvachúa et al. 2020a), and the synthesis of new-to-nature products (Martinelli and Nikel 2019). In this review, we provide an overview on the most recent and impacting developments in the field, which are shifting the industrialization of $\mathrm{P}$. putida onto a new level.

\section{Regulation of core carbon and energy metabolism}

The $P$. putida is often found in contaminated environments, which speaks in favor of a remarkable adaptation capability of the microbe to adverse conditions (Silby et al. 2011). Its atypical cyclic core metabolism, controlled on a redox demand, plays a key role to enable the high endurance observed (Chavarria et al. 2013; Nikel et al. 2015) (Fig. 3).

After entry into the periplasmic space, glucose is either internalized into the cytoplasm or oxidized in the periplasm. Gluconate (GLN) and subsequently 2 ketogluconate $(2 \mathrm{KG})$ are formed via the latter oxidation pathway. Both acids can be transported into the cytoplasm followed by phosphorylation into 6-phosphogluconate (6PG) and 6-phospho-2-ketogluconate (2K6PG). Hence, there are three different entry pathways of glucose into the core metabolism, converging at the level of 6PG (del Castillo et al. 2007). The oxidation pathways enable $P$. putida to circumvent the direct ATP-costly glucose uptake via an ABC transporter (GtsABCD) and to partially uncouple ATP formation from NADH formation. Two electrons are released in each oxidation step from periplasmic glucose to GLN and $2 \mathrm{KG}$, which is coupled to ATP generation via the ATP synthase (Ebert et al. 2011). Recently, it has been shown that glucose-grown cells generate an ATP surplus, whereas the oxidation pathway contributes significantly to the supplied ATP (Kohlstedt and Wittmann 2019). In addition, P. putida possesses an incomplete Emden-Meyerhof-Parnas (EMP) pathway, due to the absence of the key glycolytic enzyme 6phosphofructo-1-kinase (Pfk). The central intermediate $6 \mathrm{PG}$ is further catabolized almost exclusively through the Entner-Doudoroff (ED) pathway, resulting in the two C3 intermediates pyruvate (PYR) and glyceraldehyde-3-P 
Fig. 2. Typical carbon flux distribution throughout central carbon metabolism of glucosegrown Pseudomonas putida. The $P$. putida features a predominant ED pathway, coupled with an incomplete EMP pathway and activities of the PP pathway. The $\mathrm{C} 3$ intermediates, pyruvate (PYR), and glyceraldehyde-3-P (G3P), are recycled back via the gluconeogenic operation of the EMP pathway, a network topology called EDEMP cycle (Nikel et al. 2015). Respective enzymecoding genes (orange), redox and energy cofactors (light purple)

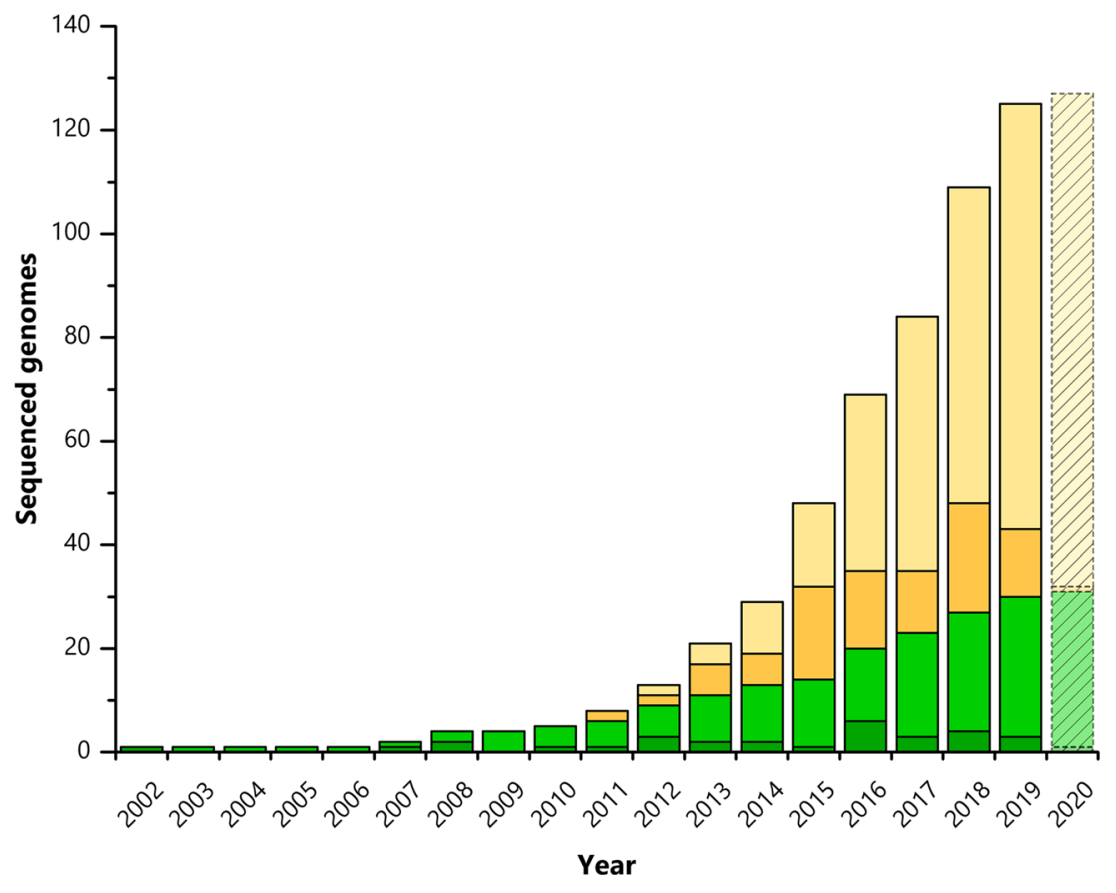

(G3P). A dominant fraction of the former enters lower catabolism. However, a significant part (approximately 10-20\% under balanced growth conditions) is recycled back to hexoses via the gluconeogenic EMP pathway, an amphibolic architecture termed as EDEMP cycle (Nikel et al. 2015). The NADPH yield is coupled to the reaction catalyzed by glucose-6-P 1-dehydrogenase (G6PDH) and, hence, depends significantly on the extent of recycling and the fraction of glucose phosphorylated via glucokinase (GLK). The ability to adjust the NADPH formation at the expense of ATP is a key factor to oxidative stress endurance in $P$. putida. This feature provides uttermost benefit in redox-demanding biocatalytic processes, which has also been shown to be important for the evolvability of novel catabolic pathways in this bacterium (Akkaya et al. 2018). Notably, de novo refactoring of the central carbon metabolism of KT2440 could be demonstrated by implementation of a functional linear glycolysis, based on the EMP pathway (Sanchez-Pascuala et al. 2017; Sánchez-Pascuala et al. 2019), which endows cells with novel tailor-made properties.

\section{Recent advances in systems biology of Pseudomonas}

A major challenge in metabolic engineering and synthetic biology is the understanding of the underlying metabolic and regulatory networks (Nogales et al. 2020), including the complex links between newly introduced and native biochemical pathways (Pandit et al. 2017). An important prerequisite to breed better cell factories is to understand the interactions occurring between the many cellular components at different functional and hierarchical levels, i.e., genome, transcriptome, proteome, metabolome, and fluxome. Recent systems biology studies, using and combining various omics technologies and collecting systems-level data in online databases, have greatly advanced our view on $P$. putida and have proven valuable to design more robust and efficient cell factories in a sophisticated manner (Poblete-Castro et al. 2013; Thompson et al. 2019).

\section{Genomics and metabolic reconstructions}

First published in 2002 and revisited in 2016, the full genome sequence of $P$. putida KT2440 has shed light on the diverse transport and metabolic systems (Belda et al. 2016; Nelson et al. 2002). Moreover, the pangenome of $P$. putida has been studied and revealed 3386 conserved genes belonging to the core genome and comprising genes related to ED and pentose phosphate (PP) pathway, proline and arginine metabolism, aromatic compound degradation, as well as a vast collection of nutrient transporters (Udaondo et al. 2016). Notably, besides sharing $85 \%$ of the coding regions with Pseudomonas aeruginosa, undesirable biotechnological traits, i.e., key virulence factors, exotoxins and type III secretion systems, are lacking in $P$. putida (Udaondo et al. 2016). Since 2010, the number of published genome sequences of $P$. putida has significantly increased (Fig. 2, Tables S1 and S2). Up to now, 28 complete genomes and 88 draft $P$. putida genomes can be accessed via the Pseudomonas genome DB (pseudomonas. com), allowing for the identification of new features for industrial application. 
Fig. 3. Available genome sequences of $P$. putida strains. Accumulated number of publicly available full (light green) and draft genome sequences (light yellow) and newly available full (dark green) and draft genome sequences (dark yellow), published in the indicated year (Data from Pseudomonas Genome DB and NCBI accessed: 05/20/2020; see Tables S1 and S2 for further information)

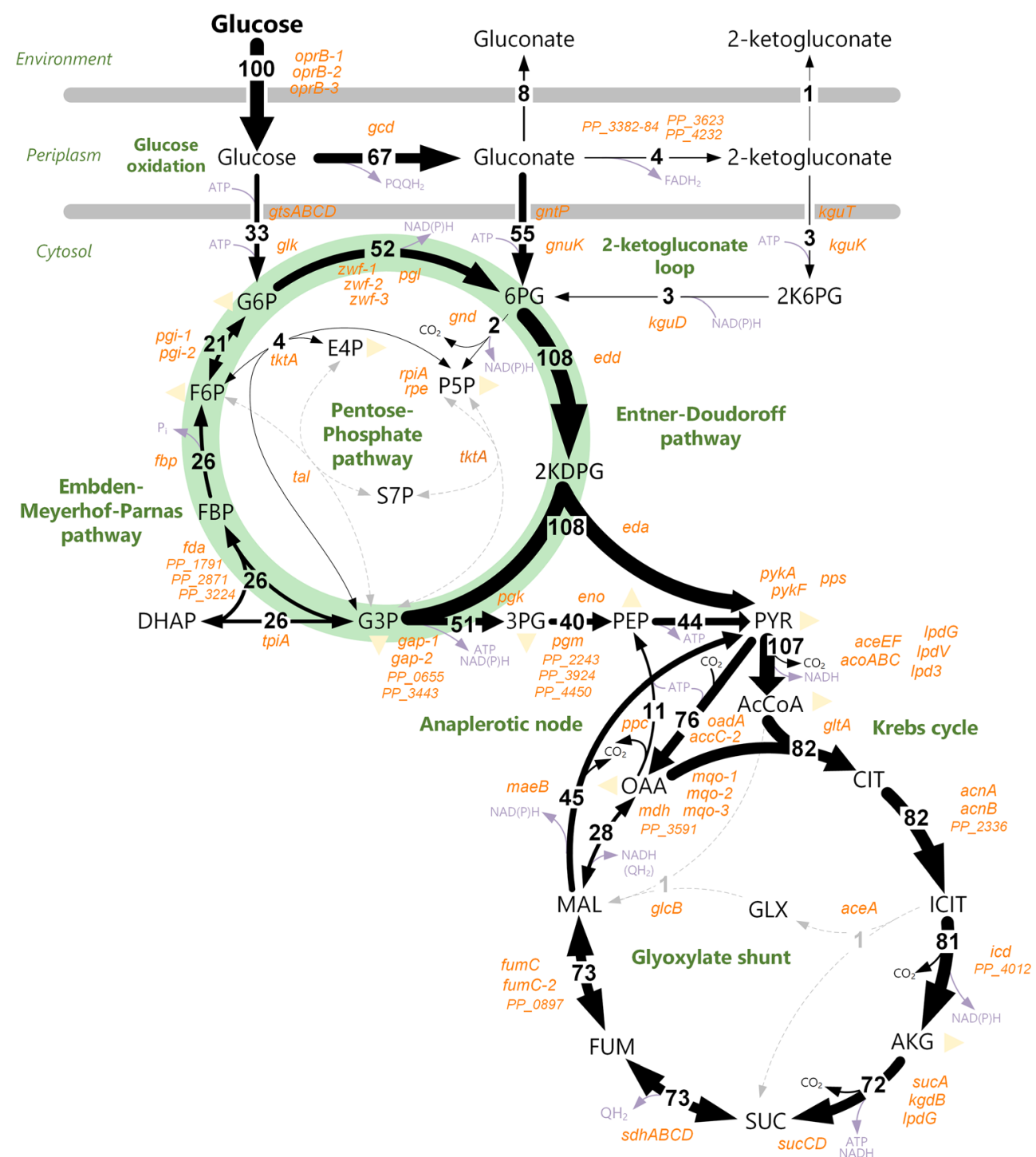

Reconstructed from sequence information, several genome-scale metabolic models (GSMM) are available for P. putida (Belda et al. 2016; Henry et al. 2010; Nogales et al. 2008; Oberhardt et al. 2011; Puchałka et al. 2008; Sohn et al. 2010; Yuan et al. 2017). Very recently, the GSMM iJN1462 of $P$. putida KT2440 was published (Nogales et al. 2020), which is comparable to high-quality Escherichia coli models in size and level of detail. With the increasing number of $P$. putida genomes available, these models can facilitate the identification of strains and enzymes most suitable for the respective industrial application and drive the design of superior producers (Buschke et al. 2013; Choi et al. 2019; Poblete-Castro et al. 2013).

\section{Transcriptomics and proteomics}

As suggested by the elevated number of open-reading frames (450 in total), encoding transcriptional factors and 24 alternative sigma subunits of the RNA polymerase, gene expression in $P$. putida is tightly regulated at the transcriptional level (Martínez-Bueno et al. 2002). Transcriptomic profiles of P. putida KT2440 grown on different substrates have been studied in response to environmental perturbations (glucose, fructose, succinate, citrate, ferulic acid, serine, and glycerol) (D'Arrigo et al. 2019; Kim et al. 2013; Nikel et al. 2014), as well as profiles during the shift between alternative carbon sources (Sudarsan et al. 2014). Furthermore, recent transcriptomic studies under osmotic, oxidative, and imipenem stress (Bojanovič et al. 2017) and increased heavy metal concentrations (Peng et al. 2018) added knowledge about the stress response mechanisms in P. putida. Notably, during exposure to solvents, a general stress response initiated the expression of molecular chaperons and other stress resistance proteins during exposure to solvents, which is favorable for biocatalysis in a hydrophobic milieu (Dominguez-Cuevas et al. 2006). More latterly, the transcriptional response during 
nitrogen-limited $m c l$-PHAs synthesis on gluconate (de novo fatty acid synthesis pathway) and oleic acid ( $\beta$-oxidation pathway) as the sole carbon sources was studied. Several genes were suggested as possible targets for strain improvement towards more efficient production (Mozejko-Ciesielska et al. 2018). Moreover, by characterizing laboratory evolved $P$. putida KT2440, utilizing genome re-sequencing and qRT-PCR, the metabolic and transcriptional regulatory bases of ethylene glycol metabolism in $P$. putida were uncovered (Li et al. 2019). Another interesting recent study mimicked repeated glucose shortage under large-scale heterogeneously mixed fermentation to investigate the metabolic and transcriptional response of $P$. putida KT2440 to starvation (Ankenbauer et al. 2020). A transcriptional regulation program linked to the intracellular pool of 3-hydroxyalkanoates, precursors of PHAs, was identified to be probably associated with accession of cellular PHA, amino acids, and glycogen to quickly restore ATP levels and the adenylate energy charge, a desired feature for large-scale bioreactors. In addition, 20 repeatedly upregulated ATP-consuming genes were promoted as possible technical targets. These genes are likely to be associated with long-term cellular programs and are superfluous in a bioreactor environment where glucose starvation is temporary (Ankenbauer et al. 2020).

Proteomics have been used to analyze $m c l$-PHA biosynthesis (Fu et al. 2015; Możejko-Ciesielska and Mostek 2019; Nikodinovic-Runic et al. 2009; Poblete-Castro et al. 2012b). Moreover, studies on post-transcriptional regulatory events, with vanillin and butanol as the sole carbon source, reported an increased abundance of enzymes of the tricarboxylic acid (TCA) cycle, indicating that this cycle is the main pathway for energy production when glucose is unavailable to $P$. putida (Simon et al. 2014; Simon et al. 2015). In addition, an increased abundance of efflux pumps and a rearrangement of transporter patterns have been shown during toluene exposure (Wijte et al. 2011). Recently, shotgun proteomics identified the oxoprolinase-encoding oplBA genes, responsible for the undesired hydrolysis of valerolactam $P$. putida, leading to a more efficient production process (Thompson et al. 2019). Besides, application of proteomics analysis and genome resequencing enhanced the understanding of the plastic monomer 1,4-butanediol metabolism in P. putida KT2440 (Li et al. 2020).

\section{Metabolomics and fluxomics}

The cyclic operation of the EDEMP pathway in P. putida has been proven by the combination of isotope labeling experiment, followed by quenching, extraction, and LC-MS analysis of intracellular intermediates of the central metabolism, and in vitro enzyme assays (Nikel et al. 2015; Sasnow et al. 2016). Lately, a high-resolution flux map of glucose-grown $P$. putida KT2440 was obtained from parallel labeling experiments using $\left[1-{ }^{13} \mathrm{C}\right]-$, $\left[6-{ }^{13} \mathrm{C}\right]$ - and $50 \%\left[{ }^{13} \mathrm{C}_{6}\right]$-glucose, and straightforward GC-MS analysis of hydrolyzed cell pellets (Kohlstedt and Wittmann 2019). By then, GC-MS-based flux studies in P. putida were extremely limited, due the unresolvable cyclic network using common flux approaches. This was circumvented by deriving the labeling patterns for G6P and F6P from an extended approach that additionally included labeling information from glycogen, lipopolysaccharides, and peptidoglycan. The novel strategy displays a breakthrough for systems biology studies of $P$. putida (Mendonca et al. 2020) and related strains (Dolan et al. 2020). At a large, metabolic flux analysis has been foremost conducted with glucose as the sole carbon source (Kohlstedt and Wittmann 2019; Nikel et al. 2015; Sasnow et al. 2016); thus, the cyclic operation of the EDEMP pathway was also demonstrated using glycerol (Beckers et al. 2016; Dolan et al. 2020) as the sole carbon source. Furthermore, these metabolic flux studies revealed an inactive glyoxylate shunt during growth on the glycolytic substrate glucose (Sasnow et al. 2016), whereas the glyoxylate shunt was found active during growth on the gluconeogenic substrate glycerol (Beckers et al. 2016) or acetate (Dolan et al. 2020). A recent study has taken up this topic by using ${ }^{13} \mathrm{C}$-metabolomics to elucidate a carbon portioning of glucose and benzoate within the metabolic network. Carbon atoms derived from glucose were cycled through the EDEMP and PP pathway, whereas benzoate was preferentially catabolized through the TCA cycle and glyoxylate shunt and the atoms derived from this substrate did not enter the EDEMP nor the PP pathway. This segregation was shown to sustain biosynthetic flux demands (Kukurugya et al. 2019) and appears an interesting feature for some bio-production processes, where a multi-substrate feeding strategy can be advantageous.

\section{Multi-omics integration}

Several studies have combined different omics approaches towards an even more complete picture. Integrating transcriptomics, proteomics, and metabolomics, the differences between nutrient conditions on PHA and biomass production in P. putida KT2442 were studied. A significantly different cellular rewiring was observed for conditions under single nutrient limitation compared with nutrient co-limitation (Poblete-Castro et al. 2012b). Moreover, carbon catabolite repression (CCR) was investigated, using a combination of metabolic, transcriptomic, and constraint-based metabolic flux analyses. It was demonstrated that central metabolic fluxes of cells grown in succinate and glucose as carbon sources are regulated by $\mathrm{CCR}$ and this regulation contributes to the organization and optimization of the metabolism and growth (La Rosa et al. 2015). Interestingly, in follow-up studies, CCR and the resulting metabolic rearrangements were also shown to be advantageous for growth in complete LB 
medium (La Rosa et al. 2016; Molina et al. 2019). Another example study investigated the cellular response of $P$. putida KT2440 on the transcriptomic, proteomic, and metabolic levels in a chemostat cultivation. The $\mathrm{C} 4$ alcohol $n$-butanol, an attractive biofuel, was used either as sole carbon source or together with glucose. Based on ${ }^{13} \mathrm{C}$-fluxome analysis, carbon portioning was observed: glucose was directed into the ED and PP pathways, and $n$-butanol fueled the TCA cycle, when both substrates were consumed. In addition, an unknown $n$ butanol degradation pathway was discovered with the help of transcriptomic and proteomic analyses (Vallon et al. 2015).

\section{Recent advances in genetic engineering}

The meanwhile large toolbox for genetic and genome engineering eases the construction workflow of reliable $P$. putida production strains. In recent years, the set of modular vectors of the Standard European Vector Architecture (SEVA) platform has turned out to be a priceless resource for construction of recombinant $P$. putida strains (Martínez-García et al. 2015; Martínez-García et al. 2019; Silva-Rocha et al. 2012). One traditionally established molecular biology resource for analyses and manipulations of $P$. putida genomes are fully synthetic derivatives of Tn5- and Tn7-based transposon vectors (Choi et al. 2005; Martínez-García et al. 2014a). The insertion of the transposon into the genome can be either random (e.g., mini-Tn5 vectors) or site specific (e.g., mini- $\operatorname{Tn} 7$ vectors). Due to the randomness of insertion, Tn5-based transposon vectors have been applied for the generation of random mutant libraries (Martinez-Garcia and de Lorenzo 2012), as well as for random insertions of entire gene clusters (Martínez-García et al. 2014a) with subsequent screening for superior phenotypes. Tn7-based transposon vectors were used to create a library of promoters and translational couplers (Zobel et al. 2015) and to optimize production of secondary metabolites (Loeschcke et al. 2013). Some of the mini transposon vectors are furthermore compatible with the SEVA format (MartínezGarcía et al. 2014a; Zobel et al. 2015). Inherently, these systems require a selection marker. Flp recombinase targetflanked antibiotic resistance determinants have been used for precise excision of selection markers with the corresponding recombinase Flp. Thus, one copy of the Flp recognition target (FRT) site will always remain after excision, limiting the repeated use of these procedures (Nikel and de Lorenzo 2013b). Subsequently, efficient genome editing methods that do not leave selection markers nor foreign DNA sequences, such as CRISPR/Cas9 technologies (Aparicio et al. 2018; Kim et al. 2020; Pham et al. 2020; Wirth et al. 2020; Zhou et al. 2020), DNA recombineering (Aparicio et al. 2020a; Aparicio et al. 2020b; Choi et al. 2018; Choi and Lee 2020), and homologous recombination-based DNA editing (Galvão and de Lorenzo 2005; Graf and Altenbuchner 2011; Martínez-García and de
Lorenzo 2011), have been developed and applied. The most widespread homologous recombination-based technique for genome engineering in $P$. putida involves two rounds of recombination. First, the suicide plasmid pEMG or derivatives, bearing recognition sequences for the intron encoded I-SceI homing endonuclease from yeast, is integrated into the genome. In the second, counter-selection step double-stranded breaks (DSB) are introduced in the genome by conditional expression of the I-SceI homing endonuclease encoded by a helper plasmid. DSBs are repaired by homologous recombination across the regions of sequence flanking the ends of the break, allowing for gene deletion, insertion, and replacement (Martínez-García and de Lorenzo 2011). Thus far, curing of the helper plasmid requires repetitive passaging of clones in antibiotic-free medium and is therefore a rather time-intensive step. Just recently, synthetic control of helper plasmid replication enabled self-curing of the plasmid in a mere overnight cultivation (Volke et al. 2020a). Moreover, fluorescent markers encoded by both the suicide plasmid and the helper plasmid eased the screening process and amenability of this approach was demonstrated by $23 \mathrm{~kb}$ genomic deletions, resulting in the streamlined strain SEM10 (Volke et al. 2020a). More recent innovative developments deal with recombineering methods, such as RecET-based markerless recombineering system for deletion and integration of largesized genes and clusters (Choi and Lee 2020), efficient singlestranded recombineering by using a thermoinducible system (Aparicio et al. 2020a), as well as CRISPR/Cas9 technologies. The latter was utilized for efficient curing of helper plasmids (Wirth et al. 2020), counterselection of infrequent mutations created through recombineering (Aparicio et al. 2018), metabolic engineering for PHA bioconversion from ferulic acid (Zhou et al. 2020), as well as CRISPR interference-mediated gene regulation (Batianis et al. 2020; Kim et al. 2020). The incredible pace of development of new tools leaves no doubt that there will be precise CRISPR-based technologies soon, speeding up genomic manipulations even further. Additionally, several tools initially developed in E. coli bear high potential to be transferred to P. putida (Martínez-García and Lorenzo 2019).

Furthermore, industrial processes require defined gene expressions by natural or synthetic promoters. Besides the already mentioned constitutive promoter libraries for chromosomal expression (Elmore et al. 2017; Kohlstedt et al. 2018; Zobel et al. 2015), another interesting study demonstrated the achievability of a wide range of chromosomal expression in P. putida (Elmore et al. 2017). Moreover, a variety of inducible promoters, both synthetic and natural, have been characterized in P. putida, as covered elsewhere (Martínez-García and de Lorenzo 2017). Recently, cell density-dependent autoinducible promoters based on the RoxS/RoxR Quorum Sensing system of $P$. putida have been developed and tested in the KT2440 strain. Theses promoter systems without the 
need of induction are especially interesting for industrial processes where protein expression independent of the addition of an inducer is desired to reduce the metabolic burden during exponential growth phase (Meyers et al. 2019). Furthermore, $r r n$ operons have demonstrated a strong preference for biosynthetic gene cluster integration in $P$. putida, due to stable integration and strong expression by the native promoters (Domröse et al. 2019). Finally, it was recently demonstrated that fine-tuning of metabolic pathways via targeted proteolysis enables a new control layer of engineered pathways (Calles et al. 2019; Volke et al. 2020b) .

\section{Pseudomonas putida as a bacterial host for industry: default beneficial built-in properties}

A microbial host needs to meet several performance criteria and quality requirements for industry, such as easy handling, predictable and reproducible production behavior, and natural robustness to ease process establishment. In fact, $P$. putida already features many desirable properties by default. Foremost, there is vast basic knowledge about $P$. putida, due to a tremendous research volume - a prerequisite for a simplified workflow for any further metabolic engineering. In a nutshell, the lessons learned about $P$. putida are the following: (a) The bacterium exhibits fast growth, high biomass yields, low to no by-product secretion and low maintenance demands (Poblete-Castro et al. 2012a). (b) The P. putida naturally sustains a surplus production of ATP and high rates of NADPH regeneration, due to EDEMP overflow metabolism on hexoses (Kohlstedt and Wittmann 2019; Nikel et al. 2015) and the metabolic routes can be also rewired to fuel the EDEMP cycle in a bottom-up fashion to enable NADPH overproduction from other gluconeogenic substrates, such as glycerol (Beckers et al. 2016). (c) The vast regulatory apparatus empowers $P$. putida with a high flexibility to quickly adjust to steady changing conditions (Kukurugya et al. 2019; Sudarsan et al. 2014), which is especially desirable in a large-scale bioreactor with heterologous microenvironments (Ankenbauer et al. 2020). (d) The microbe possesses a versatile catabolism of carbon sources. On top of that, the substrate spectrum of P. putida was successfully expanded towards the utilization of sucrose (Löwe et al. 2017), L-arabinose (Meijnen et al. 2008), D-cellobiose (Dvořák and de Lorenzo 2018), D-xylose (Bator et al. 2020; Dvořák and de Lorenzo 2018; Le Meur et al. 2012; Meijnen et al. 2008; Meijnen et al. 2009), phenol (Vardon et al. 2015), and ethylene glycol (Franden et al. 2018). Therefore, cheap, renewable feedstocks with a high level of impurities, such as glycerol, a by-product from biodiesel production (Poblete-Castro et al. 2020b), and aromatic compounds derived from lignin (Kohlstedt et al. 2018; Vardon et al. 2015), can be exploited for production of value-added chemicals. The secretion of outer membrane vesicles (OMVs) has been described as an additional mechanism for extracellular nutrient acquisition (Eberlein et al. 2019; Salvachúa et al. 2020b). (e) A high tolerance against physicochemical stress, chemical stresses (e.g., heavy metal zinc (Peng et al. 2018), cadmium (Manara et al. 2012), arsenic (Cánovas et al. 2003)), solvents (Kusumawardhani et al. 2018), and oxidative stress has been retraced inter alia to an efficient regulation machinery (Kim and Park 2014), secretion systems, trans-isomerization of the cell membrane, and changes in head group composition of cell membrane phospholipids (Ramos et al. 2015). This opens up the possibility to use biphasic systems (Verhoef et al. 2009; Wierckx et al. 2005), as well as directed laboratory evolution experiments where toxic compounds are present $(\mathrm{Li}$ et al. 2019). (f) Moreover, P. putida is naturally endowed with an elevated GC content (61-63\%) (Udaondo et al. 2016), allowing to use it for heterologous expression of genes from GC-rich microbes bearing secondary metabolite biosynthetic gene clusters, such as actino- and myxobacteria (Chai et al. 2012; Gross et al. 2006a; Gross et al. 2006b; Kimura et al. 1996; Mi et al. 2014). All these properties render P. putida an excellent host for industrial biotechnology.

\section{Pseudomonas putida as a bacterial host for industry: creation of tailor-made synthetic properties}

For the reasons mentioned previously, $P$. putida has made a reputation for being a promising microbial chassis for the bioindustry. Several research groups have started to expand its natural capacity even further. Streamlined $P$. putida strains that harbor reduced genomes offer improved characteristics, such as increased ATP and $\mathrm{NAD}(\mathrm{P}) \mathrm{H}$ availability, superior growth properties, and elevated resistance to oxidative stress (Table 1; Fig. 4).

Naturally, $P$. putida is a strict aerobic bacterium, due to the absence of fermentative pathways and the inability to use alternative electron acceptors. By tackling this problem, the performance of $P$. putida in large bioreactors can be enhanced. Synthetic fermentation pathways and nitrate/nitrite respiration were introduced in strain KT2440, which resulted in higher survival under anoxic conditions (Nikel and de Lorenzo 2013a; Steen et al. 2013). In addition, anoxic cultivation of $P$. putida was demonstrated in the anodic compartment of a bioelectrochemical system (BES), using redox mediators and an anode as extracellular electron sink to balance the intracellular redox and energy factors (Lai et al. 2016; Schmitz et al. 2015; Yu et al. 2018). The novel field of electrobiotechnology of $P$. putida provides an excellent starting point for high-yield production of sugar acids without the need for oxygen (Lai et al. 2019). Furthermore, an interesting development has managed to engineer the morphology of $P$. putida to 
Table 1. Top-down approaches for constructing streamlined $P$. putida strains

\begin{tabular}{|c|c|c|c|c|}
\hline Strain & $\begin{array}{l}\text { Genome } \\
\text { reduction }\end{array}$ & Deletion & Characteristics & Reference \\
\hline $407.1-\Delta_{2}$ & $\sim 4.4 \%$ & $\begin{array}{l}\triangle P P \_3534-P P \_3733 \\
\triangle P P \_4290-P P \_4308\end{array}$ & Similar or better growth than the wild-type strain & $\begin{array}{l}\text { Leprince et al. } \\
\text { (2012) }\end{array}$ \\
\hline $407.3-\Delta_{2}$ & $\sim 7.4 \%$ & $\begin{array}{l}\triangle P P \_3534-P P \_3733 \\
\triangle P P \_3533-P P \_3360\end{array}$ & Similar or better growth than the wild-type strain & $\begin{array}{l}\text { Leprince et al. } \\
\text { (2012) }\end{array}$ \\
\hline EM42 & $\sim 4.3 \%$ & $\begin{array}{l}\Delta \text { flagellar operon, } \Delta e n d A-1, \\
\quad \Delta \text { endA-2, } \Delta \text { prophages, } \Delta \operatorname{Tn} 7 \\
\Delta \operatorname{Tn} 4652, \Delta h s d R M S\end{array}$ & $\begin{array}{l}\text { Superior growth properties; increased energy charge, higher } \\
\text { NADPH level; improved genomic stability and plasmid structural } \\
\text { stability than strain KT2440 }\end{array}$ & $\begin{array}{l}\text { Martínez-García } \\
\text { et al. (2014b) }\end{array}$ \\
\hline EM383 & $\sim 4.3 \%$ & $\Delta r e c A$ & Derivative of EM42; improved genomic stability & $\begin{array}{l}\text { Martínez-García } \\
\text { et al. (2014b) }\end{array}$ \\
\hline SEM10 & $\sim 4.8 \%$ & $\begin{array}{l}\triangle \beta \text {-lact(-like) genes } \\
\Delta p v d D \\
\triangle \text { ben } A B C D\end{array}$ & $\begin{array}{l}\text { Derivative of EM42; Increased susceptibility towards } \beta \text {-lactam } \\
\text { antibiotics, enhanced biosafety, reduced autofluorescence, facili- } \\
\text { tated use of 3-methylbenzoate as an inducer } \\
\text { (no colored by-products) }\end{array}$ & $\begin{array}{l}\text { Volke et al. } \\
\quad(2020 \mathrm{a})\end{array}$ \\
\hline EM371 & $\sim 4.7 \%$ & $\begin{array}{l}\Delta \text { flagellum } \\
\Delta \text { fimbriae } \\
\Delta \text { surface adherence proteins } \\
\Delta \text { EPS } \\
\Delta \text { O-antigen side chain } \\
\Delta \operatorname{Tn} 7 \\
\Delta \text { prophage } 4\end{array}$ & $\begin{array}{l}\text { Improved accessibility of the cell surface, improved genomic } \\
\text { stability, improved resistance to UV than strain KT2440 }\end{array}$ & $\begin{array}{l}\text { Martinez-Garcia } \\
\text { et al. (2020) }\end{array}$ \\
\hline KTU-U13 & $\sim 4.1 \%$ & $\Delta$ genomic islands & $\begin{array}{l}\text { Similar growth, increased plasmid stability, } \\
\text { potential improvement of expression level of heterologous } \\
\text { proteins }\end{array}$ & $\begin{array}{l}\text { Liang et al. } \\
\quad(2020)\end{array}$ \\
\hline
\end{tabular}

render the lifestyle from a planktonic towards a biofilm-based one, which can exhibit a higher tolerance to harsh reaction conditions during biotransformations (Benedetti et al. 2016). This is an unique property of Pseudomonas species, where the whole-cell catalyst can be manipulated to adopt a spatial configuration that greatly facilitates the purification of extracellular products (Volke and Nikel 2018). Moreover, autodisplay of enzymes can be advantageous in some whole-cell biocatalytic approaches: Being connected to the cell as a matrix, the surface-displayed biocatalyst is readily stabilized and purified and substrates and products do not necessarily need to cross the membrane barrier (Jose 2006). Recently, an improved autotransporter-based surface display of an esterase and a $\beta$ glucosidase was demonstrated using $P$. putida KT2440, utilizing the native $P$. putida OprF signal peptide (Tozakidis et al. 2020). Very promising, in order to make the cell surface more accessible to the outer medium, 230 genes were deleted from the parent strain P. putida KT2440 ( 4,7\% genome reduction size), including surface adhesion proteins, exopolysaccharides, fimbriae, the $O$-antigen side chain, the flagellum, and other envelope-associated components (Martinez-Garcia et al. 2020). The resulting strain EM371 displays a platform strain for artificial adhesins, which was already used for the successful display of designer protein scaffolds on the surface of $P$. putida cells, opening up the possibility to engineer artificial cellulosomes (Dvořák et al. 2020a). Under harsh bioprocess conditions, however, the degree of surface exposure may need to be further tweaked, since the larger cell surface contact area of EM371 also leads to an increased sensitivity to external stressors (MartinezGarcia et al. 2020).

\section{Bioproduction and industrial application}

Not surprisingly, works on biotechnological application of this bacteria evaluated and conceived $P$. putida for its use in bioremediation (de Lorenzo 2008; Jiménez et al. 2002; Shim and Yang 1999; Udiković-Kolić et al. 2012), as a biocontrol agent and plant growth-promoting bacteria (Gouda et al. 2018; Matilla and Krell 2018). Furthermore, the application spectrum of $P$. putida has grown considerably over the last few years and $P$. putida has proven to be an excellent bacterial host to produce polymers, bulk chemicals, drugs, and highprice specialties (Fig. 5).

\section{Polyhydroxyalkanoates}

Endopolymeric mcl-PHAs are naturally synthesized by $P$. putida as a carbon and energy storage compound under specific conditions, such as carbon excess during nutrient limitation $\left(\mathrm{N}, \mathrm{O}_{2}, \mathrm{P}, \mathrm{S}\right)$ (Poblete-Castro et al. 2012b). The family of PHA polyesters is one of the best-known product classes studied in Pseudomonas species (Prieto et al. 2016). 


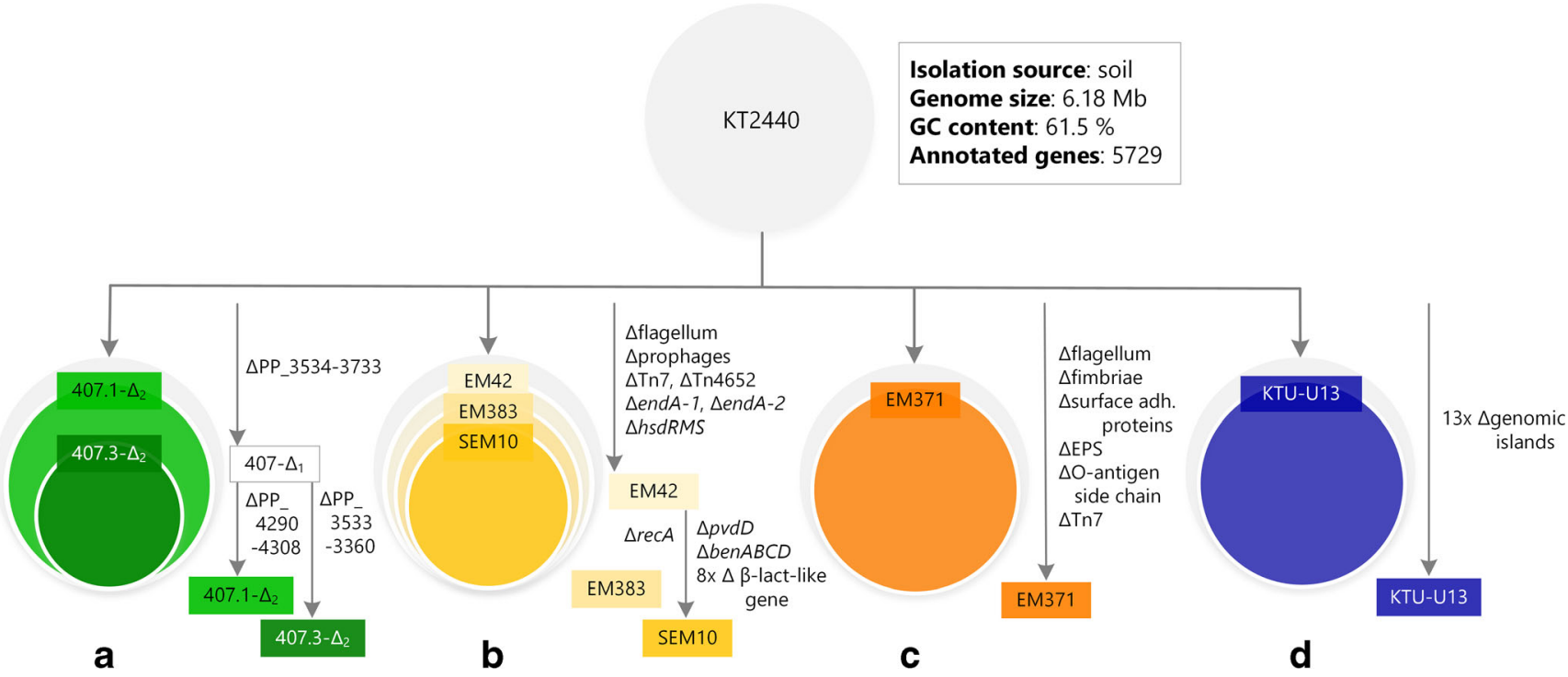

Fig. 4. Genome-reduced strains of P. putida KT2440 constructed to date. The diagram represents the genealogy of parent strain KT2440 and its genome reduced derivatives. (a) Cyclic, random large-scale deletions using a mini-Tn 5 transposon combined with the FLP-FRT recombination system. A first deletion round resulted in strain $407-\Delta_{1}$ (gray box; $\triangle P P$ 3534-PP 3733), and subsequent deletion rounds resulted in strains 407.1- $\Delta_{2}$ (light green; $\triangle P P \_4290-P P \_4308$ ) and 407.3- $\Delta_{2}$ (dark green; $\triangle P P$ 3533-PP 3360). (b) Large target deletions, using the homologous recombination-based I-SceI methodology of the flagellar operon $(\triangle P P$ 4329-PP_4397), 4 prophage elements, Tn7 transposase and $\operatorname{Tn} 465 \overline{2}$ transposon, deoxyribonucleases I encoded in endA-1 and endA-2, and the hsdRMS operon ( $\left.\triangle P P \_4740-P P \_4742\right)$ encoding a I DNA

restriction-modification system resulted in strain EM42 (yellow). Further deletion of recA resulted in strain EM383, and elimination of eight $\beta$-lactamase(-like) genes, $p v d D$ (involved in siderophore formation), and the ben $A B C D$ gene cluster led to strain SEM10. (c) Large target deletions, utilizing the I-SceI methodology, of genes encoding flagellum, fimbriae, surface adhesion proteins, exopolysaccharides, $O$-antigen side chain, and envelope-associated compounds and Tn7-like transposase operon (orange). (d) Large target deletion of 13 genomic islands using an upp-based counter-selection system resulted in strain KTU-U13 (blue). Reduced genome sizes, depicted as smaller cycles than that of strain $\mathrm{KT} 2440$, are not drawn to scale of genome reduction

PHAs offer an excellent alternative for petroleum-based plastics, due to their biodegradability and competitive material properties, such as biocompatibility, lack of toxicity, insolubility, and thermostability (Mozejko-Ciesielska et al. 2019). The structural composition of PHAs can be adjusted by feeding of precursors (Wang et al. 2010), cultivation conditions, and strain engineering (Tripathi et al. 2013). The companies Kaneka (Japan), Telles (USA), Jiangsu Nantian (China), Tianjin GreenBio (China), Tepha (USA), DSM (The Netherlands), Biomer Biotechnology (Germany), Bioon (Italy), Polyferm (Canada), and Biomatera (Canada) report to produce PHA polymers on an industrial scale using P. putida (Poltronieri and Kumar 2017). The global PHA market size is expected to grow from US\$ 57 million in 2019 to US\$ 98 by 2024, wherein the major constrain for growth is the cost competitiveness to conventional polymers (MarketsandMarkets ${ }^{\mathrm{TM}}$ 2019). The P. putida can produce mcl-PHAs from a broad spectrum of carbon sources, giving the opportunity to use cheap renewable feedstocks, such as crude glycerol from biodiesel production (Poblete-Castro et al. 2014), plant-derived fatty acids (Cerrone et al. 2014), food waste (Follonier et al. 2014), lignin-derived aromatics (Liu et al. 2017; Salvachúa et al. 2020a), and even nondegradable plastic waste, PET monomers (Kenny et al.
2008). In recent studies, the first production of PHAs from cellobiosan, levoglucosan (Linger et al. 2016), and cellobiose (Dvořák et al. 2020b) was reported. The $P$. putida EM42expressing $\mathrm{bglC}$ from Thermobifida fusca, encoding $\beta$-glucosidase, accumulates $m c l$-PHA and concomitantly secretes xylonate, a platform chemical (Dvořák et al. 2020b). Such co-production of valuable bioproducts from low-cost substrates along with PHA represents a good opportunity to mitigate the overall PHA production costs ( $\mathrm{Li}$ et al. 2017). Besides feedstock costs, downstream processing and product recovery is an important cost factor for the industrial production of intracellular compounds, which needs to be addressed to make the industrial application economical feasible. Some of the conventional methods include solvent extraction and chemical digestion. However, these methods are also marked with possible environmental drawbacks, high costs, or degradation of the polymer. Recently, a recovery of nearly $94 \%$ of the synthesized $m c l$-PHA after $3 \mathrm{~h}$ could be shown with cell disruption through a programmable cell lysis system in $P$. putida KT2440 engineered to respond to osmotic state (Poblete-Castro et al. 2020a). Taken together, recent achievements will pave the way to further reduce process costs at the level of raw material selection and downstream processing. 


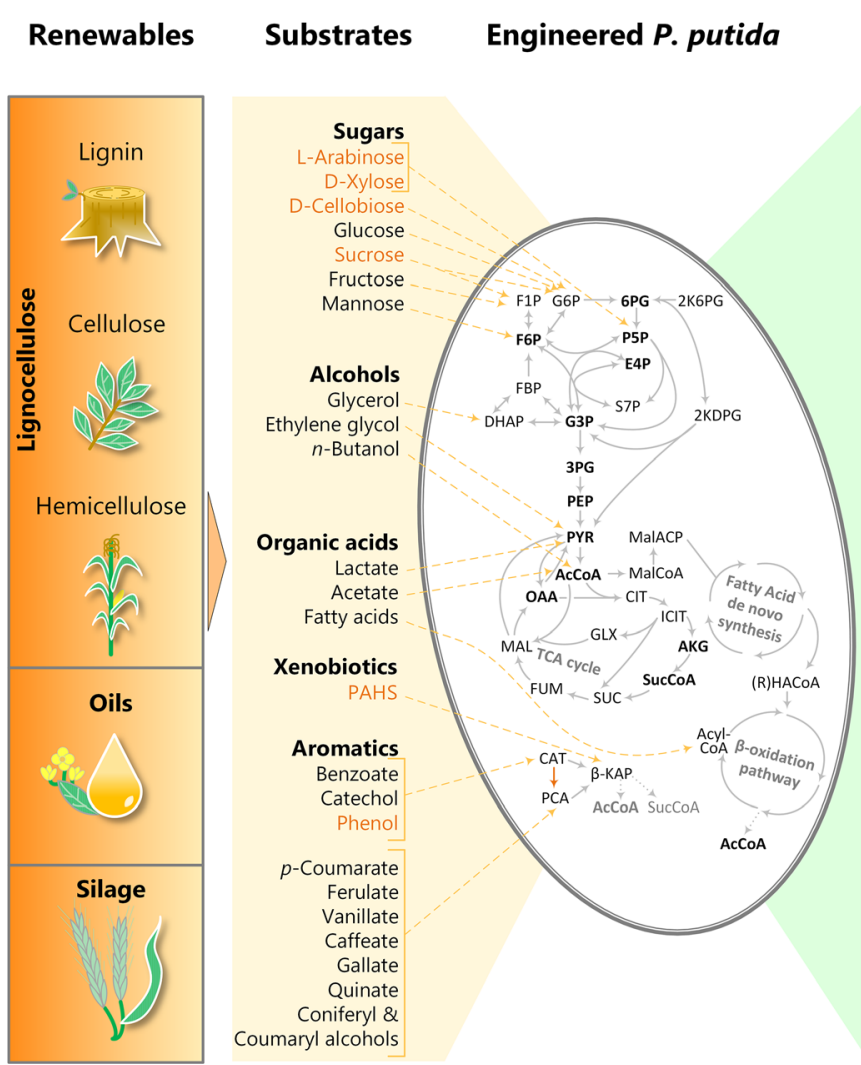

Fig. 5. Bioproduction using engineered $P$. putida strains. Substrates generated from renewable feedstocks, such as lignocellulose, oils and silage can be used to produce value added products for application in the food and feed $(\Delta)$, health and hygiene $(\boldsymbol{\vee})$, packaging and housing

\section{Alginates}

Even though less studied, $P$. putida can produce exopolymeric alginates (Conti et al. 1994) and dehydration has been suggested as the general signal for the production of this polysaccharides (Chang et al. 2007). Alginate is a common additive to cosmetics and foods and has many medical applications. However, up to now, alginate production has been mainly studied in the pathogenic $P$. aeruginosa and there has been no commercial application associated to these efforts (Liu et al. 2019; Valentine et al. 2020).

\section{Cis,cis-muconic acid}

The arsenal of oxidoreductases, mono- and dioxygenases encoded in the genome of $P$. putida, enables this bacterium to degrade a variety of aromatic compounds found in the renewable feedstock lignin (Nogales et al. 2017). The aromatics are channeled through catabolic funneling via the $\beta$ ketoadipate $(\beta-\mathrm{KA})$ pathway converging in only a few central intermediates (i.e., catechol, protocatechuate (PCA)), which are ring-cleaved and further converted into TCA cycle intermediates. One intermediate of this pathway, cis, cis-muconic acid (MA), is a very promising molecule, as it can be used as a
Products

Applications

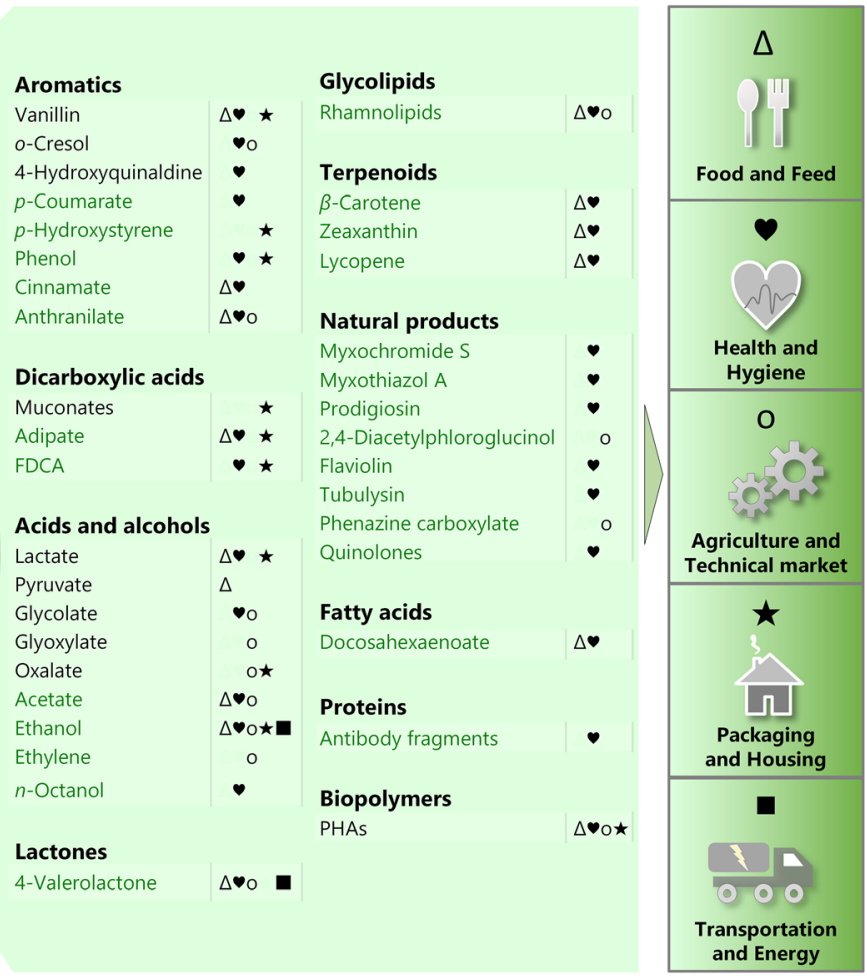

$(\star)$, transportation and energy sector $(\boldsymbol{\bullet})$, and for agriculture and technical application (o). Entry points of the respective substrates in the metabolism (dashed orange line), new to $P$. putida substrates (orange) and products (green)

starting material for the synthesis of value-added chemicals, such as caprolactam, terephthalic and adipic acid, as well as a bulk chemical in polymer reactions for the production of muconic homo- and copolymers (Khalil et al. 2020). Upon disruption of the degradation route at the level of muconate cycloisomerase (CatB), a stoichiometric conversion of aromatic substrates into MA can be achieved (van Duuren et al. 2011). Several studies reported successful MA production using P. putida KT2440 (Johnson et al. 2017; Johnson et al. 2016; Kohlstedt et al. 2018; Salvachúa et al. 2018; Sonoki et al. 2018; van Duuren et al. 2012; van Duuren et al. 2011; Vardon et al. 2015). In a landmark study, the biotransformation of a broad range of aromatic monomers, namely protocatechuate, ferulate, coniferyl alcohol, vanillin, caffeate, $p$-coumarate, 4-hydroxybenzoate (feeding into the PCA branch) and catechol, benzoate, and phenol (fueling the catechol branch), into MA was demonstrated. For this purpose, the PCA branch of $\beta$-KA pathway was connected to the catechol branch by heterologous expression of PCA decarboxylase encoded by the aroY gene from Enterobacter cloacae, with a simultaneous disruption of the natural PCA degradation route catalyzed by protocatechuate 3,4-dioxygenase (PcaHG). As a result and important proof of concept, $0.7 \mathrm{~g} \mathrm{~L}^{-1} \mathrm{MA}$ was produced from alkaline pretreated liquor $-\mathrm{a}$ waste stream 
from bioethanol production (Vardon et al. 2015). However, for some aromatic monomers tested, accumulation of intermediates was observed, indicating an inefficient conversion to MA (Vardon et al. 2015). Subsequently, improvement of MA production efficiency from aromatics of the PCA branch was achieved by increasing PCA decarboxylase activity via co-expression of accessory proteins ecdBD from E. cloacae (Johnson et al. 2016) and by tackling this bottleneck on the regulatory level by eliminating CCR (Johnson et al. 2017). Since all lignin-derived aromatics eventually merge at the level of the highly toxic intermediate catechol, this node is of interest as metabolic engineering target. In a seminal study, during processing of toxic catechol, cellular energy limitation was identified as a major challenge (Kohlstedt et al. 2018). To overcome this drawback on the operation side, implemented specific feed pauses during fed-batch fermentation allowed the regeneration of cellular energy levels and a final MA titer of $64.2 \mathrm{~g} \mathrm{~L}^{-1}$ from catechol was obtained, exceeding previously reported values by more than tenfold. A second strategy reported in this study created superior KT2440 cell factories. Several rounds of metabolic engineering resulted in an improved platform strain for catechol conversion: increased catechol 1,2-dioxygenase activity by implementing a copy of the catA2 gene (natively directly downstream of the catA gene under control of the native $\mathrm{P}_{\text {cat }}$ promoter). Thereby, a strongly improved tolerance to catechol and a higher catechol degradation rate could be achieved. The developed process was transferred to pilot-scale-producing MA at the kilogram scale with $98 \%$ purity. Subsequently, by heterologous expression of a phenolhydroxylase, the strain is now able to additionally convert phenol into MA and cresols into methylated derivatives of MA. The final strain produced $13 \mathrm{~g} \mathrm{~L}^{-1} \mathrm{MA}$ from a softwood lignin hydrolysate (Kohlstedt et al. 2018). Engineered strains for MA are no longer able to grow on aromatics; therefore, glucose is commonly used as the growth substrate. Recently, a study reported glucose-independent MA production using engineered KT2440. This strain was able to produce small amounts $\left(20 \mathrm{mg} \mathrm{L}^{-1}\right)$ of MA from depolymerized softwood lignin (Sonoki et al. 2018). Moreover, MA production was also achieved using glucose as the sole substrate (Bentley et al. 2020; Johnson et al. 2019).

\section{Adipic acid and nylon 66}

To showcase the entire value chain from lignin to bio-based nylon, MA underwent hydrogenation to adipic acid, a precursor for commercial nylon-66 (Kohlstedt et al. 2018; Vardon et al. 2015; Vardon et al. 2016). The combined chemical and biochemical process is displayed in Fig. 6. A recent limited life cycle assessment concluded the feasibility of the biobased production of adipic acid from softwood ligninderived aromatics based on P. putida as the whole-cell biocatalyst (van Duuren et al. 2020) and even possible offset credits were promoted for the bioethanol biorefinery, if the lignin in the their wastewater is no longer burnt but converted to the value-added product adipic acid instead (Corona et al. 2018). Purification of MA produced by $P$. putida from lignin model compounds by activated carbon treatment was demonstrated with a good recovery at $>97 \%$ purity. Subsequently, Pd/Caided catalytic hydrogenation of MA yielded bio-based adipic acid (Vardon et al. 2015).

Recently, the feasibility of direct de novo synthesis of adipic acid from lignin model compounds was demonstrated using P. putida KT2440 (Niu et al. 2020). To this end, the pathway design profited from the C6 structure of the $\beta$-KA pathway intermediate 3-ketoadipoyl-CoA, i.e., there is no need to exploit a condensation reaction between an acetyl$\mathrm{CoA}$ and a succinyl-CoA unit as previously reported for adipic acid biosynthesis using glucose- or glycerol-grown E. coli (Cheong et al. 2016; Yu et al. 2014; Zhao et al. 2018).

\section{2,5-Furandicarboxylic acid}

The important platform chemical hydroxymethyl furfuraldehyde (HMF) can be derived from mono- and polysaccharides and pre-treated biomass (Dutta et al. 2012). Further catalytic oxidation of HMF yields the building block 2,5-furandicarboxylic acid (FDCA), which has potential applications in the production of plasticizers, polyamides, and polyesters (Corbion 2020; Sousa et al. 2015). One polymer of particular interest is polyethylene furanoate (PEF), a copolymer of ethylene glycol and FDCA, which represents an ideal substituent for polyethylene terephthalate (PET) in packaging, due to its exceptional thermal and superior barrier properties (Sousa et al. 2015). It may also serve as precursor for poly (1,4cyclohexanedimethylene furandicarboxylate (PCF) (Wang et al. 2018). The global FDCA market is growing with an assessment at US\$243.9 million in 2020 and is expected increase to US\$321.3 million by the end of 2026 (QY Research 2020). Companies, such as Stora Enso (Stora Enso 2019), Novamont (Novamont 2019), and Avantium (2023: 5000 tons/year) (Avantium 2020) are currently entering the market with the construction of (pilot) plants for the production of biomass-derived FDCA. Whereas, chemocatalysis is the predominant route for the production of FDCA, which exhibits some disadvantages, such as costly metal catalysts, utilization of organic solvents, and the requirement of high temperature and pressure (Yuan et al. 2020). However, biocatalytic approaches are hindered by the toxic biological effects of furan aldehydes, attributable to ROS-induced oxidative stress (Allen et al. 2010; Almeida et al. 2009). Engineered $P$. putida KT2440 was able to grow on HMF and furfural as the sole carbon source after heterologous expression of the catabolic HMF and furfural gene clusters from Burkholderia phytofirmans (Guarnieri et al. 2017). For biotransformation of HMF to FDCA, P. putida S12 was chosen as a host, due to its 


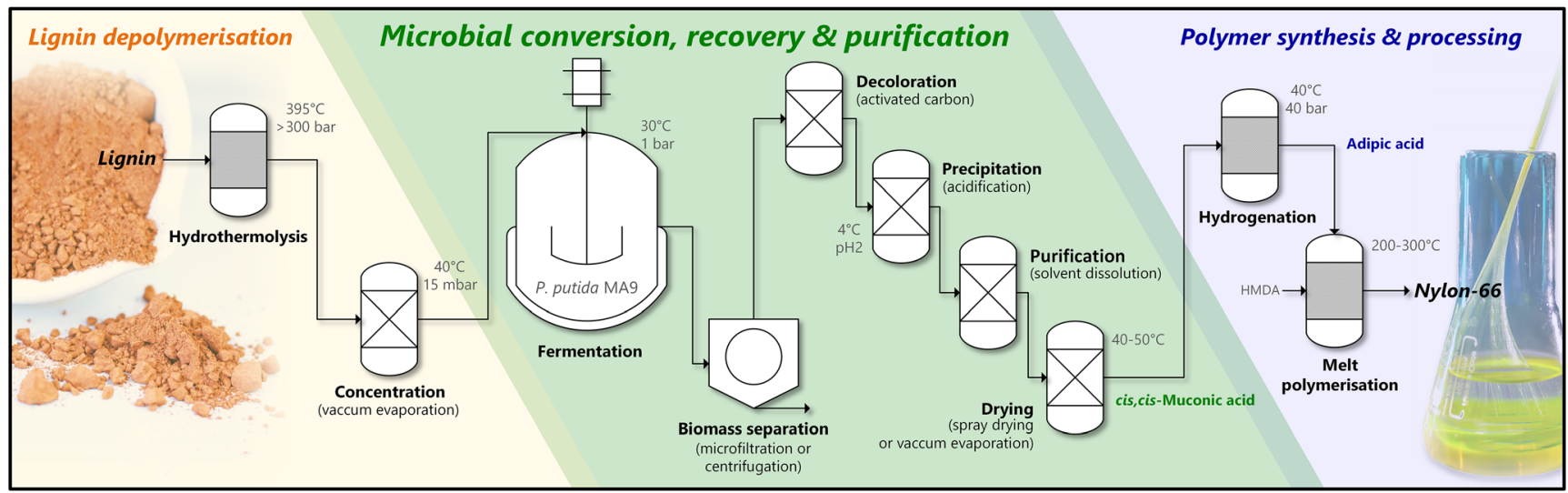

Fig. 6. Cascaded biochemical and chemical route for nylon-66 production using metabolically engineered $P$. putida. Lignin depolymerization, microbial conversion of aromatic monomers to MA, subsequent product

natural tolerance to chemical stressors and the availability of endogenous aldehyde dehydrogenases to oxidize HMF to its corresponding, less toxic carboxylic acid (Koopman et al. 2010). By episomally expressing the oxidoreductase encoding hmfH gene from Cupriavidus basilensis HMF14, the efficient production of FDCA was reported for the first time, using a whole-cell transformation (Koopman et al. 2010). Subsequently, FDCA production was optimized by episomal coexpression of $h m f H$, aldehyde hydrogenase $a d h$ and $h m f T 1$ transporter gene from C. basilensis HMF14 in P. putida, resulting in high, reproducible production rates (Wierckx et al. 2012). Recently, chromosomal co-integration of $h m f H$ and $h m f T 1$ in P. putida $\mathrm{S} 12$ was demonstrated by coupling $\lambda$ Red-mediated recombineering with CRISPR/Cas9 technology (Pham et al. 2020). Very promising, application of the patent dealing with FDCA production from HMF, using P. putida is filed by a subsidiary of Corbion, a company which is active in the industrial production of PEF derived from FDCA (Corbion; Wierckx et al. 2012).

\section{Aromatics}

The natural tolerance and ability to metabolize aromatics have been exploited for the region-selective bioproduction of 3-methylcatechol (Hüsken et al. 2001), the bioproduction of $o$-cresol from toluene in a two-phase 1octanol/water system (Faizal et al. 2006), as well as epoxidation of styrene in a water/octanol two-liquid phase system (Blank et al. 2008). Other produced building blocks include pyruvate and lactate from $p$-coumarate and benzoate (Johnson and Beckham 2015). Moreover, the bioconversion of ferulic acid to the flavor agent vanillin was achieved with resting cells (Graf and Altenbuchner 2014). Interestingly, in this study, the sole deletion of the vanillin dehydrogenase gene $(v d h)$ did not suppress degradation of the later and one hitherto unknown molybdate-dependent oxidoreductase was found to probably complement the recovery and purification, hydrogenation to adipic acid and final polycondensation with hexamethylenediamine (HMDA) to nylon-66 (Kohlstedt et al. 2018)

$v d h$ inactivation. The natural tolerance of $P$. putida towards aromatic compounds has not only been exploited for bioconversions and -transformations, but also for de novo synthesis of aromatic compounds originating from shikimate pathway intermediates. Using the solvent-tolerant $P$. putida S12 strain production of cinnamic acid (Nijkamp et al. 2005), phenol in a biphasic fed batch cultivation system with octanol (Wierckx et al. 2005) and $p$-hydroxystyrene in a water/1-decanol phase (Verhoef et al. 2009) were reported. Anthranilate, $p$-coumaric acid, and parahydroxybenzoic acid were synthesized from glucose by KT2440-derived strains (Calero et al. 2016; Kuepper et al. 2015; Yu et al. 2016).

\section{Biosurfactants}

Rhamnolipids are biodegradable and low toxic biosurfactants. The activity of biosurfactants enhances the solubility of hydrophobic molecules in water by decreasing the surface tension (Rehm 2009). Potential applications can be found in food industry, cosmetics, cleaning agents, biocontrol, and soil remediation (Fracchia et al. 2014; Loeschcke and Thies 2015). The $P$. putida is able to produce short-chain rhamnolipids after heterologous integration of the $\operatorname{rhl} A B(C)$ operon from $P$. aeruginosa (Tiso et al. 2017; Wittgens et al. 2011) and long-chain rhamnolipids after expression of $r h l$ genes from Burkholderia glumae (Wittgens et al. 2018). Wherein, the chain length depends on the respective expressed $r h l$ genes rather than the available 3-hydroxy fatty acids, a property which can be used for the production of tailor-made rhamnolipids (Wittgens et al. 2018). The chemical company Evonik Industries (Essen, Germany) announced the first industrial production of rhamnolipids in 2016 (Evonik Industries 2016), followed by an issued patent in 2017 for rhamnolipid production from $n$-butane by $P$. putida KT2440 (Thum et al. 2017). 


\section{Terpenoids}

The high tolerance of $P$. putida against the toxicity of intermediates or terminal products has proven to be advantageous to produce terpenoids, one of the largest and structurally diverse groups of natural compounds. Taking the natural resistance into advantage, the successful de novo production of geranic acid, a monoterpenoid with several reported antibiotic activities and uses as flavor and fragrance agent, could be shown. This study also revealed a remarkably higher resistance of $P$. putida to more than 6-fold higher product concentrations in comparison to E. coli and Saccharomyces cerevisiae (Mi et al. 2014). Furthermore, oxy-functionalized derivatives of specific terpenoids are sometimes desired for their specific bioactivities. Naturally, such derivatives only occur in low amounts and both their isolation and their chemical synthesis are rather uneconomical. Thus, in vivo enzymatic transformation of toxic monoterpenoids by heterologously expressed cytochrome P450 monooxygenases as an alternative is under study. As an example, the conversion of limonene to perillic acid (Mirata et al. 2009; van Beilen et al. 2005) and the hydroxylation of 1,8-cineole (Mi et al. 2016) was achieved. In addition, another class of terpenoids, the carotenoids zeaxanthin and $\beta$-carotene, has been successfully produced in P. putida (Beuttler et al. 2011; Loeschcke et al. 2013). In this context, the astonishing metabolic plasticity of $P$. putida was demonstrated by reshaping the native, cyclical EDEMP pathway into a linear EMP pathway by heterologous expression of glycolytic genes from E. coli. This led to increased levels of PYR and G3P, both precursors of carotenoid production, resulting in 1.3-fold increase in carotenoid production compared with the parental strain (Sánchez-Pascuala et al. 2019). Further increase of precursor supply seems to be a crucial factor for efficient production.

\section{Polyketides and non-ribosomal peptides}

Polyketides (PKs) and non-ribosomal peptides (NRPs) display diverse groups of natural products that have commonly medically relevant activities. Both are assembled by condensation of simple carboxylic or amino acid building blocks. The produced polymers can be cyclized and decorated to form the final product. The PKs 2,4-diacetylphloroglucinol (Martinez et al. 2004) and the UV-protective pigment flaviolin (Gross et al. 2006a) were successfully produced in P. putida. An interesting PK/NRP hybrid compound is the antibiotic prodigiosin, due to its anticancer and immunosuppressant activities (Domröse et al. 2015). In E. coli prodigiosin transcription is inhibited (Danevčič et al. 2016). Yet, this is not the case for $P$. putida. The TREX expression system, which includes elements of transposon Tn5, enabled the random chromosomal integration of the pig gene cluster, derived from the native producer Serratia marcescens W83. Remarkably, a higher titer could be reached using a strong intrinsic chromosomal promoter (Domröse et al. 2015) compared with utilization of a synthetic T7 RNA polymerase-dependent promoter (Loeschcke et al. 2013). This study led to the discovery of rRNA promoters as strong native promoters for heterologous expression of biosynthetic gene clusters in $P$. putida (Domröse et al. 2019). Furthermore, through the expression of myxobacterial hybrid systems, the antibiotics myxochromide S (Stephan et al. 2006) and tubulysin (Chai et al. 2012) could be synthesized. Since many of the biosynthetic gene clusters required for the production of natural products are larger than $6 \mathrm{~kb}$ (Loeschcke and Thies 2015), sophisticated tools are needed for chromosomal integration. One such tool is the recent developed RecET-based markerless recombineering system for $P$. putida (Choi and Lee 2020). The site-specific integration of a 7.4-kb violacein cluster could be shown (Choi et al. 2018). Moreover, the first synthetic polyketide synthase-like pathway for the production of the omega-3 fatty acid docosahexaenoic acid (DHA) was successfully expressed in P. putida KT2440 (Gemperlein et al. 2016).

\section{Recombinant protein production}

The expression of antibodies in P. putida KT2440 could be achieved with proper folding and promising yields (Dammeyer et al. 2011; Jiménez et al. 2015). In addition, whole-cell $P$. putida or isolated enzymes thereof find actual industrial application (Poblete-Castro et al. 2012a; Rehm 2009; Tiso et al. 2014). An example company is DSM (The Netherlands), which has reported to produce chiral compounds using isolated enzymes from P. putida ATCC 12633 (Hermes et al. 1993; Rehm 2009). Whole-cell P. putida biocatalysts are enabled to produce 5-cyanopentanamide (DiCosimo et al. 1996), D-p-hydroxyphenyl glycine (Schulze and Wubbolts 1999), and 5-methylpyrazine-2carboxylic acid (Kiener 1992). Furthermore, strain BIRD-1 is commercially available as plant growth-promoting bacterium (Fosfogel, Bio-Iliberis R\&D, Granada, Spain).

\section{Conclusion and outlook}

The choice of microbial hosts for biotechnological applications had long been based on historical tradition (Calero and Nikel 2019) rather than on the bacterial chassis (platform) which meets the desired process criteria in the best possible way. This is mainly because microorganisms that have been extensively investigated and characterized can be more easily manipulated to maximize production, and concurrently their behavior during industrial scale-up is more predictable. Recent advantages in synthetic and systems biology tools support turning the tide of the choice of microbial host 
for industry (Wehrs et al. 2019). This is especially true for $P$. putida. Long known for its versatile metabolism and low nutritional requirements (Timmis 2002), recent advances in omics technologies now enable the discovery of new attractive features of representatives by genome sequencing, the decryption of the central core and energy metabolism by flux analysis (Kohlstedt and Wittmann 2019; Nikel et al. 2015), and the regulation of gene expression on the transcriptional and translational levels. Findings thereof, together with improvements of genetic engineering tools, are of particular value to complete our holistic understanding of $P$. putida and ease the development of superior industrial strains. Moreover, it should be stressed that the capability of producing value-added chemicals from alternative feedstocks (Kohlstedt et al. 2018; Poblete-Castro et al. 2014; Salvachúa et al. 2020a; Wierckx et al. 2012) is a superior feature to pass into the envisaged circular bioeconomy. Beyond the wide product range already demonstrated for $P$. putida, a promising upcoming approach is re-designing the biochemical portfolio by introducing complete synthetic pathways (bio-bricks) to access new-tonature products, such as halogenated molecules and boron-containing structures in the near future (NietoDomínguez and Nikel 2020; Nikel and de Lorenzo 2018). This will open a full new branch of biotechnologically producible molecules and represents an important step regarding the limited fossil-based resources. However, as in the case of other microbes (Wehrs et al. 2019), despite extensive studies and demonstration of feasibility of production on a small scale, large-scale industrial applications of $P$. putida do not yet add up in numbers, with PHA, FDCA, and rhamnolipid production as rare exceptions, as discussed previously. Nevertheless, successful proof-ofconcept studies and product life cycle assessments are important starting points for subsequent process optimization and development of viable business cases. But more importantly, they underline the extraordinary metabolic versatility and robustness of $P$. putida as serious player, who will ultimately contribute to a greener and more sustainable cradle-to-cradle economy.

Authors' contributions C.W. conceptualized and designed the review. A.W., M.K., and C.W. wrote the first draft of the manuscript. All authors critically commented, extended, improved, and approved the final manuscript.

Funding information Open Access funding provided by Projekt DEAL. A.W., M.K., and C.W. acknowledge funding by the Federal Ministry of Education and Research (BMBF) through the grants Bio2Nylon (grant no. 03V0757) and LignoValue (grant no. 031B0344A) and by the State Government of the Saarland through the grant NINA. P.I.N. acknowledges the financial support by the Novo Nordisk Foundation (grants NNF10CC1016517 and NNF18OC0034818), the European Union's Horizon 2020 Research and Innovation Program under grant agreement no. 814418 (SinFonia), and the Danish Council for Independent Research (SWEET, DFF-Research Project 8021-00039B).

\section{Compliance with ethical standards}

Conflict of interests M.K. and C.W. have filed patent applications on the use of engineered $P$. putida strains for bio-production from ligninbased aromatics. P.I.N. has filed patent applications on the use of engineered $P$. putida strains to produce novel halogenated molecules.

Open Access This article is licensed under a Creative Commons Attribution 4.0 International License, which permits use, sharing, adaptation, distribution and reproduction in any medium or format, as long as you give appropriate credit to the original author(s) and the source, provide a link to the Creative Commons licence, and indicate if changes were made. The images or other third party material in this article are included in the article's Creative Commons licence, unless indicated otherwise in a credit line to the material. If material is not included in the article's Creative Commons licence and your intended use is not permitted by statutory regulation or exceeds the permitted use, you will need to obtain permission directly from the copyright holder. To view a copy of this licence, visit http://creativecommons.org/licenses/by/4.0/.

\section{References}

Akkaya Ö, Pérez-Pantoja DR, Calles B, Nikel PI, de Lorenzo V (2018) The metabolic redox regime of Pseudomonas putida tunes its evolvability toward novel xenobiotic substrates. mBio 9(4): e01512-e01518. https://doi.org/10.1128/mBio.01512-18

Allen SA, Clark W, McCaffery JM, Cai Z, Lanctot A, Slininger PJ, Liu ZL, Gorsich SW (2010) Furfural induces reactive oxygen species accumulation and cellular damage in Saccharomyces cerevisiae. Biotechnol Biofuels 3(1):2. https://doi.org/10.1186/1754-6834-3-2

Almeida JRM, Bertilsson M, Gorwa-Grauslund MF, Gorsich S, Lidén G (2009) Metabolic effects of furaldehydes and impacts on biotechnological processes. Appl Microbiol Biotechnol 82(4):625-638. https://doi.org/10.1007/s00253-009-1875-1

Ankenbauer A, Schäfer RA, Viegas SC, Pobre V, Voß B, Arraiano CM, Takors R (2020) Pseudomonas putida KT2440 is naturally endowed to withstand industrial-scale stress conditions. Microb Biotechnol: https://doi.org/10.1111/1751-7915.13571

Aparicio T, de Lorenzo V, Martínez-García E (2018) CRISPR/Cas9based counterselection boosts recombineering efficiency in Pseudomonas putida. Biotechnol J 13(5):1700161. https://doi.org/ 10.1002/biot.201700161

Aparicio T, Nyerges A, Martínez-García E, de Lorenzo V (2020a) Highefficiency multi-site genomic editing of Pseudomonas putida through thermoinducible ssDNA recombineering. iScience 23(3): 100946. https://doi.org/10.1016/j.isci.2020.100946

Aparicio T, Nyerges A, Nagy I, Pal C, Martínez-García E, de Lorenzo V (2020b) Mismatch repair hierarchy of Pseudomonas putida revealed by mutagenic ssDNA recombineering of the pyrF gene. Environ Microbiol 22(1):45-58. https://doi.org/10.1111/1462-2920.14814

Avantium (2020) Avantium to build FDCA flagship plant at Chemie Park Delfzijl, Netherlands. Publisher. https:/www.avantium.com/2020/ avantium-to-build-fdca-flagship-plant-at-chemie-park-delfzijlnetherlands/ Accessed 20/05/20

Batianis C, Kozaeva E, Damalas SG, Martín-Pascual M, Volke DC, Nikel PI, Martins dos Santos VAP (2020) An expanded CRISPRi toolbox for tunable control of gene expression in Pseudomonas putida. Microb Biotechnol 13(2):368-385. https://doi.org/10.1111/ 1751-7915.13533 
Bator I, Wittgens A, Rosenau F, Tiso T, Blank LM (2020) Comparison of three xylose pathways in Pseudomonas putida KT2440 for the synthesis of valuable products. Front Bioeng Biotechnol 7(480). https:// doi.org/10.3389/fbioe.2019.00480

Beckers V, Poblete-Castro I, Tomasch J, Wittmann C (2016) Integrated analysis of gene expression and metabolic fluxes in PHA-producing Pseudomonas putida grown on glycerol. Microb Cell Factories 15(1):73. https://doi.org/10.1186/s12934-016-0470-2

Belda E, van Heck RGA, José Lopez-Sanchez M, Cruveiller S, Barbe V, Fraser C, Klenk H-P, Petersen J, Morgat A, Nikel PI, Vallenet D, Rouy Z, Sekowska A, Martins dos Santos VAP, de Lorenzo V, Danchin A, Médigue C (2016) The revisited genome of Pseudomonas putida KT2440 enlightens its value as a robust metabolic chassis. Environ Microbiol 18(10):3403-3424. https://doi. org/10.1111/1462-2920.13230

Benedetti I, de Lorenzo V, Nikel PI (2016) Genetic programming of catalytic Pseudomonas putida biofilms for boosting biodegradation of haloalkanes. Metab Eng 33:109-118

Bentley GJ, Narayanan N, Jha RK, Salvachúa D, Elmore JR, Peabody GL, Black BA, Ramirez K, De Capite A, Michener WE, Werner AZ, Klingeman DM, Schindel HS, Nelson R, Foust L, Guss AM, Dale T, Johnson CW, Beckham GT (2020) Engineering glucose metabolism for enhanced muconic acid production in Pseudomonas putida KT2440. Metab Eng 59:64-75. https://doi. org/10.1016/j.ymben.2020.01.001

Beuttler H, Hoffmann J, Jeske M, Hauer B, Schmid RD, Altenbuchner J, Urlacher VB (2011) Biosynthesis of zeaxanthin in recombinant Pseudomonas putida. Appl Microbiol Biotechnol 89(4):11371147. https://doi.org/10.1007/s00253-010-2961-0

Blank LM, Ionidis G, Ebert BE, Bühler B, Schmid A (2008) Metabolic response of Pseudomonas putida during redox biocatalysis in the presence of a second octanol phase. FEBS J 275(20):5173-5190. https://doi.org/10.1111/j.1742-4658.2008.06648.x

Bojanovič K, D'Arrigo I, Long KS (2017) Global transcriptional responses to osmotic, oxidative, and imipenem stress conditions in Pseudomonas putida. Appl Environ Microbiol 83(7):e03236e03216. https://doi.org/10.1128/aem.03236-16

Buschke N, Schafer R, Becker J, Wittmann C (2013) Metabolic engineering of industrial platform microorganisms for biorefinery applications - optimization of substrate spectrum and process robustness by rational and evolutive strategies. Bioresour Technol 135:544-554. https://doi.org/10.1016/j.biortech.2012.11.047

Calero P, Nikel PI (2019) Chasing bacterial chassis for metabolic engineering: a perspective review from classical to non-traditional microorganisms. Microb Biotechnol 12(1):98-124

Calero P, Jensen SI, Nielsen AT (2016) Broad-host-range ProUSER vectors enable fast characterization of inducible promoters and optimization of p-coumaric acid production in Pseudomonas putida KT2440. ACS Synth Biol 5(7):741-753. https://doi.org/10.1021/ acssynbio.6b00081

Calles B, Goñi-Moreno Á, de Lorenzo V (2019) Digitalizing heterologous gene expression in Gram-negative bacteria with a portable ON/ OFF module. Mol Syst Biol 15(12):e8777. https://doi.org/10.15252/ $\mathrm{msb} .20188777$

Cánovas D, Cases I, De Lorenzo V (2003) Heavy metal tolerance and metal homeostasis in Pseudomonas putida as revealed by complete genome analysis. Environ Microbiol 5(12):1242-1256. https://doi. org $/ 10.1111 /$ j. $1462-2920.2003 .00463 . x$

Cerrone F, Choudhari SK, Davis R, Cysneiros D, O'Flaherty V, Duane G, Casey E, Guzik MW, Kenny ST, Babu RP, O’Connor K (2014) Medium chain length polyhydroxyalkanoate (mcl-PHA) production from volatile fatty acids derived from the anaerobic digestion of grass. Appl Microbiol Biotechnol 98(2):611-620. https://doi.org/ 10.1007/s00253-013-5323-x

Chai Y, Shan S, Weissman Kira J, Hu S, Zhang Y, Müller R (2012) Heterologous expression and genetic engineering of the tubulysin biosynthetic gene cluster using Red/ET recombineering and inactivation mutagenesis. Chem Biol 19(3):361-371. https://doi.org/10. 1016/j.chembiol.2012.01.007

Chang W-S, van de Mortel M, Nielsen L, Nino de Guzman G, Li X, Halverson LJ (2007) Alginate production by Pseudomonas putida creates a hydrated microenvironment and contributes to biofilm architecture and stress tolerance under water-limiting conditions. J Bacteriol 189(22):8290-8299. https://doi.org/10.1128/jb.00727-07

Chavarria M, Nikel PI, Perez-Pantoja D, de Lorenzo V (2013) The Entner-Doudoroff pathway empowers Pseudomonas putida KT2440 with a high tolerance to oxidative stress. Environ Microbiol 15(6): 1772-1785

Cheong S, Clomburg JM, Gonzalez R (2016) Energy- and carbonefficient synthesis of functionalized small molecules in bacteria using non-decarboxylative Claisen condensation reactions. Nat Biotechnol 34(5):556-561. https://doi.org/10.1038/nbt.3505

Choi KR, Lee SY (2020) Protocols for RecET-based markerless gene knockout and integration to express heterologous biosynthetic gene clusters in Pseudomonas putida. Microb Biotechnol 13(1):199-209. https://doi.org/10.1111/1751-7915.13374

Choi EN, Cho MC, Kim Y, Kim C-K, Lee K (2003) Expansion of growth substrate range in Pseudomonas putida F1 by mutations in both cymR and todS, which recruit a ring-fission hydrolase $\mathrm{CmtE}$ and induce the tod catabolic operon, respectively. Microbiology 149(3): 795-805. https://doi.org/10.1099/mic.0.26046-0

Choi K-H, Gaynor JB, White KG, Lopez C, Bosio CM, KarkhoffSchweizer RR, Schweizer HP (2005) A Tn7-based broad-range bacterial cloning and expression system. Nat Methods 2(6):443-448. https://doi.org/10.1038/nmeth765

Choi KR, Cho JS, Cho IJ, Park D, Lee SY (2018) Markerless gene knockout and integration to express heterologous biosynthetic gene clusters in Pseudomonas putida. Metab Eng 47:463-474. https:// doi.org/10.1016/j.ymben.2018.05.003

Choi KR, Jang WD, Yang D, Cho JS, Park D, Lee SY (2019) Systems metabolic engineering strategies: integrating systems and synthetic biology with metabolic engineering. Trends Biotechnol 37(8):817837. https://doi.org/10.1016/j.tibtech.2019.01.003

Conti E, Flaibani A, Apos, Regan M, Sutherland IW (1994) Alginate from Pseudomonas fluorescens and P. putida: production and properties. Microbiology 140(5):1125-1132. https://doi.org/10.1099/ 13500872-140-5-1125

Cook TB, Rand JM, Nurani W, Courtney DK, Liu SA, Pfleger BF (2018) Genetic tools for reliable gene expression and recombineering in Pseudomonas putida. J Ind Microbiol Biotechnol 45(7):517-527. https://doi.org/10.1007/s10295-017-2001-5

Corbion The future of plastics is biobased. Publisher. https://www. corbion.com/bioplastics/fdca Accessed 14.05.2020

Corona A, Biddy M, Vardon D, Birkved M, Hauschild M, Beckham G (2018) Life cycle assessment of adipic acid production from lignin. Green Chem 20. https://doi.org/10.1039/c8gc00868j

Dammeyer T, Steinwand M, Krüger S-C, Dübel S, Hust M, Timmis KN (2011) Efficient production of soluble recombinant single chain Fv fragments by a Pseudomonas putida strain KT2440 cell factory. Microb Cell Factories 10:11-11. https://doi.org/10.1186/14752859-10-11

Danevčič T, Borić Vezjak M, Zorec M, Stopar D (2016) Prodigiosin—a multifaceted Escherichia coli antimicrobial agent. PLoS One 11(9): e0162412-e0162412. https://doi.org/10.1371/journal.pone. 0162412

D'Arrigo I, Cardoso JGR, Rennig M, Sonnenschein N, Herrgard MJ, Long KS (2019) Analysis of Pseudomonas putida growth on nontrivial carbon sources using transcriptomics and genome-scale modelling. Environ Microbiol Rep 11(2):87-97

de Lorenzo V (2008) Systems biology approaches to bioremediation. Curr Opin Biotechnol 19(6):579-589. https://doi.org/10.1016/j. copbio.2008.10.004 
del Castillo T, Ramos JL, Rodríguez-Herva JJ, Fuhrer T, Sauer U, Duque E (2007) Convergent peripheral pathways catalyze initial glucose catabolism in Pseudomonas putida: genomic and flux analysis. J Bacteriol 189(14):5142-5152. https://doi.org/10.1128/jb.00203-07

DiCosimo R, Stieglitz B, Fallon RD (1996) Production of $\omega$ cyanocarboxamides from aliphatic $\alpha, \omega$-dinitriles using pseudomonas putida-derived biocatalysts US5728556A,

Dolan SK, Kohlstedt M, Trigg S, Vallejo Ramirez P, Kaminski CF, Wittmann C, Welch M (2020) Contextual flexibility in Pseudomonas aeruginosa central carbon metabolism during growth in single carbon sources. mBio 11(2):e02684-e02619. https://doi. org/10.1128/mBio.02684-19

Dominguez-Cuevas P, Gonzalez-Pastor JE, Marques S, Ramos JL, de Lorenzo V (2006) Transcriptional tradeoff between metabolic and stress-response programs in Pseudomonas putida KT2440 cells exposed to toluene. J Biol Chem 281(17):11981-11991

Domröse A, Klein A, Hage-Hülsmann J, Thies S, Svensson V, Classen T, Pietruszka J, Jaeger K-E, Drepper T, Loeschcke A (2015) Efficient recombinant production of prodigiosin in Pseudomonas putida. Front Microbiol 6(972). https://doi.org/10.3389/fmicb.2015.00972

Domröse A, Hage-Hülsmann J, Thies S, Weihmann R, Kruse L, Otto M, Wierckx N, Jaeger K-E, Drepper T, Loeschcke A (2019) Pseudomonas putida rDNA is a favored site for the expression of biosynthetic genes. Sci Rep 9(1):7028. https://doi.org/10.1038/ s41598-019-43405-1

Duan J, Jiang W, Cheng Z, Heikkila JJ, Glick BR (2013) The complete genome sequence of the plant growth-promoting bacterium Pseudomonas sp. UW4. PLoS One 8(3):e58640. https://doi.org/ 10.1371/journal.pone.0058640

Dutta S, De S, Saha B, Alam MI (2012) Advances in conversion of hemicellulosic biomass to furfural and upgrading to biofuels. Catal Sci Technol 2(10):2025-2036. https://doi.org/10.1039/c2cy20235b

Dvořák P, de Lorenzo V (2018) Refactoring the upper sugar metabolism of Pseudomonas putida for co-utilization of cellobiose, xylose, and glucose. bioRxiv: 284182. https://doi.org/10.1101/284182

Dvořák P, Nikel PI, Damborský J, de Lorenzo V (2017) Bioremediation 3.0: engineering pollutant-removing bacteria in the times of systemic biology. Biotechnol Adv 35(7):845-866. https://doi.org/10.1016/ j.biotechadv.2017.08.001

Dvořák P, Bayer EA, de Lorenzo V (2020a) Surface display of designer protein scaffolds on genome-reduced strains of Pseudomonas putida. bioRxiv:2020.05.13.093500. https://doi.org/10.1101/2020. 05.13.093500

Dvořák P, Kováč J, de Lorenzo V (2020b) Biotransformation of d-xylose to d-xylonate coupled to medium-chain-length polyhydroxyalkanoate production in cellobiose-grown Pseudomonas putida EM42. Microb Biotechnol https://doi.org/10. 1111/1751-7915.13574

Eberlein C, Starke S, Doncel ÁE, Scarabotti F, Heipieper HJ (2019) Quantification of outer membrane vesicles: a potential tool to compare response in Pseudomonas putida KT2440 to stress caused by alkanols. Appl Microbiol Biotechnol 103(10):4193-4201. https:// doi.org/10.1007/s00253-019-09812-0

Ebert BE, Kurth F, Grund M, Blank LM, Schmid A (2011) Response of Pseudomonas putida KT2440 to increased NADH and ATP demand. Appl Environ Microbiol 77(18):6597-6605. https://doi.org/ 10.1128/aem.05588-11

Elmore JR, Furches A, Wolff GN, Gorday K, Guss AM (2017) Development of a high efficiency integration system and promoter library for rapid modification of Pseudomonas putida KT2440. Metab Eng Commun 5:1-8. https://doi.org/10.1016/j.meteno.2017. 04.001

Evonik Industries (2016) Evonik comercializes biosurfactants. Publisher. http://corporate.evonik.com/en/media/press releases/pages/newsdetails.aspx?newsid=60276 Accessed 16 Apr 2020
Faizal I, Dozen K, Hong C, Kuroda A, Takiguchi N, Ohtake H, Takeda $\mathrm{K}$, Tsunekawa H, Kato J (2006) Isolation and characterization of solvent-tolerant Pseudomonas putida strain T-57, and its application to biotransformation of toluene to cresol in a two-phase (organicaqueous) system. J Ind Microbiol Biotechnol 32:542-547. https:// doi.org/10.1007/s10295-005-0253-y

Follonier S, Goyder MS, Silvestri A-C, Crelier S, Kalman F, Riesen R, Zinn M (2014) Fruit pomace and waste frying oil as sustainable resources for the bioproduction of medium-chain-length polyhydroxyalkanoates. Int J Biol Macromol 71:42-52. https://doi. org/10.1016/j.ijbiomac.2014.05.061

Fracchia L, Ceresa C, Franzetti A, Cavallo M, Gandolfi I, Van Hamme J, Gkorezis P, Marchant R, Banat I (2014) Industrial applications of biosurfactants. In: Vardar Sukan F, Kosaric N (eds) Biosurfactants: production and utilization - processes, technologies, and economics, vol 159. CRC Press, Boca Raton, pp 245-268

Franden MA, Jayakody LN, Li W-J, Wagner NJ, Cleveland NS, Michener WE, Hauer B, Blank LM, Wierckx N, Klebensberger J, Beckham GT (2018) Engineering Pseudomonas putida KT2440 for efficient ethylene glycol utilization. Metab Eng 48:197-207. https:// doi.org/10.1016/j.ymben.2018.06.003

Fu J, Sharma P, Spicer V, Krokhin OV, Zhang X, Fristensky B, Cicek N, Sparling R, Levin DB (2015) Quantitative omics analyses of medium chain length polyhydroxyalkanaote metabolism in Pseudomonas putida LS46 cultured with waste glycerol and waste fatty acids. PLoS One 10(11):e0142322. https://doi.org/10.1371/ journal.pone. 0142322

Galvão TC, de Lorenzo V (2005) Adaptation of the yeast URA3 selection system to Gram-negative bacteria and generation of a $\triangle$ betCDE Pseudomonas putida Strain. Appl Environ Microbiol 71(2):883892. https://doi.org/10.1128/aem.71.2.883-892.2005

Gemperlein K, Zipf G, Bernauer HS, Müller R, Wenzel SC (2016) Metabolic engineering of Pseudomonas putida for production of docosahexaenoic acid based on a myxobacterial PUFA synthase. Metab Eng 33:98-108

Glick B (2012) Plant growth-promoting bacteria: mechanisms and applications. Scientifica 2012:963401. https://doi.org/10.6064/2012/ 963401

Gouda S, Kerry RG, Das G, Paramithiotis S, Shin H-S, Patra JK (2018) Revitalization of plant growth promoting rhizobacteria for sustainable development in agriculture. Microbiol Res 206:131-140. https://doi.org/10.1016/j.micres.2017.08.016

Graf N, Altenbuchner J (2011) Development of a method for markerless gene deletion in Pseudomonas putida. Appl Environ Microbiol 77(15):5549-5552. https://doi.org/10.1128/aem.05055-11

Graf N, Altenbuchner J (2014) Genetic engineering of Pseudomonas putida KT2440 for rapid and high-yield production of vanillin from ferulic acid. Appl Microbiol Biotechnol 98(1):137-149. https://doi. org/10.1007/s00253-013-5303-1

Gross F, Luniak N, Perlova O, Gaitatzis N, Jenke-Kodama H, Gerth K, Gottschalk D, Dittmann E, Müller R (2006a) Bacterial type III polyketide synthases: phylogenetic analysis and potential for the production of novel secondary metabolites by heterologous expression in Pseudomonads. Arch Microbiol 185(1):28-38. https://doi.org/10. 1007/s00203-005-0059-3

Gross F, Ring MW, Perlova O, Fu J, Schneider S, Gerth K, Kuhlmann S, Stewart AF, Zhang Y, Muller R (2006b) Metabolic engineering of Pseudomonas putida for methylmalonyl-CoA biosynthesis to enable complex heterologous secondary metabolite formation. Chem Biol 13(12):1253-1264

Guarnieri MT, Ann Franden M, Johnson CW, Beckham GT (2017) Conversion and assimilation of furfural and 5(hydroxymethyl)furfural by Pseudomonas putida KT2440. Metab Eng Commun 4:22-28. https://doi.org/10.1016/j.meteno.2017.02. 001 
Henry CS, DeJongh M, Best AA, Frybarger PM, Linsay B, Stevens RL (2010) High-throughput generation, optimization and analysis of genome-scale metabolic models. Nat Biotechnol 28(9):977-982. https://doi.org/10.1038/nbt.1672

Hermes HF, Sonke T, Peters PJ, van Balken JA, Kamphuis J, Dijkhuizen L, Meijer EM (1993) Purification and characterization of an 1aminopeptidase from Pseudomonas putida ATCC 12633. Appl Environ Microbiol 59(12):4330-4334

Hüsken L, Beeftink H, Bont JAM, Wery J (2001) High-rate 3methylcatechol production in Pseudomonas putida strains by means of a novel expression system. Appl Microbiol Biotechnol 55:571577. https://doi.org/10.1007/s002530000566

Jiménez JI, Miñambres B, García JL, Díaz E (2002) Genomic analysis of the aromatic catabolic pathways from Pseudomonas putida KT2440. Environ Microbiol 4(12):824-841. https://doi.org/10. 1046/j.1462-2920.2002.00370.x

Jiménez JI, Fraile S, Zafra O, de Lorenzo V (2015) Phenotypic knockouts of selected metabolic pathways by targeting enzymes with camelderived nanobodies (VHHs). Metab Eng 30:40-48. https://doi.org/ 10.1016/j.ymben.2015.04.002

Johnson CW, Beckham GT (2015) Aromatic catabolic pathway selection for optimal production of pyruvate and lactate from lignin. Metab Eng 28:240-247

Johnson CW, Salvachua D, Khanna P, Smith H, Peterson DJ, Beckham GT (2016) Enhancing muconic acid production from glucose and lignin-derived aromatic compounds via increased protocatechuate decarboxylase activity. Metab Eng Commun 3:111-119. https:// doi.org/10.1016/j.meteno.2016.04.002

Johnson CW, Abraham PE, Linger JG, Khanna P, Hettich RL, Beckham GT (2017) Eliminating a global regulator of carbon catabolite repression enhances the conversion of aromatic lignin monomers to muconate in Pseudomonas putida KT2440. Metab Eng Commun 5: 19-25. https://doi.org/10.1016/j.meteno.2017.05.002

Johnson CW, Salvachúa D, Rorrer NA, Black BA, Vardon DR, St. John PC, Cleveland NS, Dominick G, Elmore JR, Grundl N, Khanna P, Martinez CR, Michener WE, Peterson DJ, Ramirez KJ, Singh P, VanderWall TA, Wilson AN, Yi X, Biddy MJ, Bomble YJ, Guss AM, Beckham GT (2019) Innovative chemicals and materials from bacterial aromatic catabolic pathways. Joule 3(6):1523-1537. https://doi.org/10.1016/j.joule.2019.05.011

Jose J (2006) Autodisplay: efficient bacterial surface display of recombinant proteins. Appl Microbiol Biotechnol 69:607-614. https://doi. org/10.1007/s00253-005-0227-Z

Kenny ST, Runic JN, Kaminsky W, Woods T, Babu RP, Keely CM, Blau W, O'Connor KE (2008) Up-cycling of PET (polyethylene terephthalate) to the biodegradable plastic PHA (polyhydroxyalkanoate). Environ Sci Technol 42(20):7696-7701. https://doi.org/10.1021/es801010e

Khalil I, Quintens G, Junkers T, Dusselier M (2020) Muconic acid isomers as platform chemicals and monomers in the biobased economy. Green Chem doi. https://doi.org/10.1039/c9gc04161c

Kiener A (1992) Enzymatic oxidation of methyl groups on aromatic heterocycles: a versatile method for the preparation of heteroaromatic carboxylic acids. Angew Chem Int Ed Engl 31(6): 774-775. https://doi.org/10.1002/anie.199207741

Kim J, Park W (2014) Oxidative stress response in Pseudomonas putida. Appl Microbiol Biotechnol 98(16):6933-6946. https://doi.org/10. 1007/s00253-014-5883-4

Kim J, Oliveros JC, Nikel PI, de Lorenzo V, Silva-Rocha R (2013) Transcriptomic fingerprinting of Pseudomonas putida under alternative physiological regimes. Environ Microbiol Rep 5(6):883-891

Kim SK, Yoon PK, Kim S-J, Woo S-G, Rha E, Lee H, Yeom S-J, Kim H, Lee D-H, Lee S-G (2020) CRISPR interference-mediated gene regulation in Pseudomonas putida KT2440. Microb Biotechnol 13(1): 210-221. https://doi.org/10.1111/1751-7915.13382
Kimura H, Miyashita H, Sumino Y (1996) Organization and expression in Pseudomonas putida of the gene cluster involved in cephalosporin biosynthesis from Lysobacter lactamgenus YK90. Appl Microbiol Biotechnol 45(4):490-501

Kohler KA, Ruckert C, Schatschneider S, Vorholter FJ, Szczepanowski R, Blank LM, Niehaus K, Goesmann A, Puhler A, Kalinowski J, Schmid A (2013) Complete genome sequence of Pseudomonas sp. strain VLB120 a solvent tolerant, styrene degrading bacterium, isolated from forest soil. J Biotechnol 168(4):729-730

Kohlstedt M, Wittmann C (2019) GC-MS-based ${ }^{13} \mathrm{C}$ metabolic flux analysis resolves the parallel and cyclic glucose metabolism of Pseudomonas putida KT2440 and Pseudomonas aeruginosa PAO1. Metab Eng 54:35-53

Kohlstedt M, Starck S, Barton N, Stolzenberger J, Selzer M, Mehlmann K, Schneider R, Pleissner D, Rinkel J, Dickschat JS, Venus J, van Duuren JBJH, Wittmann C (2018) From lignin to nylon: cascaded chemical and biochemical conversion using metabolically engineered Pseudomonas putida. Metab Eng 47:279-293. https:// doi.org/10.1016/j.ymben.2018.03.003

Koopman F, Wierckx N, de Winde JH, Ruijssenaars HJ (2010) Efficient whole-cell biotransformation of 5-(hydroxymethyl)furfural into FDCA, 2,5-furandicarboxylic acid. Bioresour Technol 101(16): 6291-6296

Kuepper J, Dickler J, Biggel M, Behnken S, Jäger G, Wierckx N, Blank LM (2015) Metabolic engineering of Pseudomonas putida KT2440 to produce anthranilate from glucose. Front Microbiol 6(1310). https://doi.org/10.3389/fmicb.2015.01310

Kukurugya MA, Mendonca CM, Solhtalab M, Wilkes RA, Thannhauser TW, Aristilde L (2019) Multi-omics analysis unravels a segregated metabolic flux network that tunes co-utilization of sugar and aromatic carbons in Pseudomonas putida. J Biol Chem 294(21):84648479. https://doi.org/10.1074/jbc.ra119.007885

Kusumawardhani H, Hosseini R, de Winde JH (2018) Solvent tolerance in bacteria: fulfilling the promise of the biotech era? Trends Biotechnol 36(10):1025-1039. https://doi.org/10.1016/j.tibtech. 2018.04.007

La Rosa R, Nogales J, Rojo F (2015) The Crc/CrcZ-CrcY global regulatory system helps the integration of gluconeogenic and glycolytic metabolism in Pseudomonas putida. Environ Microbiol 17(9): 3362-3378. https://doi.org/10.1111/1462-2920.12812

La Rosa R, Behrends V, Williams HD, Bundy JG, Rojo F (2016) Influence of the $\mathrm{Crc}$ regulator on the hierarchical use of carbon sources from a complete medium in Pseudomonas. Environ Microbiol 18(3):807-818. https://doi.org/10.1111/1462-2920. 13126

Lai B, Yu S, Bernhardt PV, Rabaey K, Virdis B, Krömer JO (2016) Anoxic metabolism and biochemical production in Pseudomonas putida $\mathrm{F} 1$ driven by a bioelectrochemical system. Biotechnol Biofuels 9:39-39. https://doi.org/10.1186/s13068-016-0452-y

Lai B, Nguyen AV, Krömer JO (2019) Characterizing the anoxic phenotype of Pseudomonas putida using a bioelectrochemical system. Methods Protoc 2(2):26. https://doi.org/10.3390/mps2020026

Le Meur S, Zinn M, Egli T, Thony-Meyer L, Ren Q (2012) Production of medium-chain-length polyhydroxyalkanoates by sequential feeding of xylose and octanoic acid in engineered Pseudomonas putida KT2440. BMC Biotechnol 12(53):1472-6750

Leprince A, de Lorenzo V, Völler P, van Passel MWJ, Martins dos Santos VAP (2012) Random and cyclical deletion of large DNA segments in the genome of Pseudomonas putida. Environ Microbiol 14(6): 1444-1453. https://doi.org/10.1111/j.1462-2920.2012.02730.x

Li T, Elhadi D, Chen G-Q (2017) Co-production of microbial polyhydroxyalkanoates with other chemicals. Metab Eng 43:29 36. https://doi.org/10.1016/j.ymben.2017.07.007

Li W-J, Jayakody LN, Franden MA, Wehrmann M, Daun T, Hauer B, Blank LM, Beckham GT, Klebensberger J, Wierckx N (2019) Laboratory evolution reveals the metabolic and regulatory basis of 
ethylene glycol metabolism by Pseudomonas putida KT2440. Environ Microbiol 21(10):3669-3682. https://doi.org/10.1111/ 1462-2920.14703

Li W-J, Narancic T, Kenny ST, Niehoff P-J, O’Connor K, Blank LM, Wierckx N (2020) Unraveling 1,4-butanediol metabolism in Pseudomonas putida KT2440. Front Microbiol 11(382). https:// doi.org/10.3389/fmicb.2020.00382

Liang P, Zhang Y, Xu B, Zhao Y, Liu X, Gao W, Ma T, Yang C, Wang S, Liu R (2020) Deletion of genomic islands in the Pseudomonas putida KT2440 genome can create an optimal chassis for synthetic biology applications. Microb Cell Factories 19(1):70. https://doi. org/10.1186/s12934-020-01329-w

Linger JG, Hobdey SE, Franden MA, Fulk EM, Beckham GT (2016) Conversion of levoglucosan and cellobiosan by Pseudomonas putida KT2440. Metab Eng Commun 3:24-29. https://doi.org/10. 1016/j.meteno.2016.01.005

Liu Z-H, Olson ML, Shinde S, Wang X, Hao N, Yoo CG, Bhagia S, Dunlap JR, Pu Y, Kao KC, Ragauskas AJ, Jin M, Yuan JS (2017) Synergistic maximization of the carbohydrate output and lignin processability by combinatorial pretreatment. Green Chem 19(20): 4939-4955. https://doi.org/10.1039/c7gc02057k

Liu J, Yang S, Li X, Yan Q, Reaney MJT, Jiang Z (2019) Alginate oligosaccharides: production, biological activities, and potential applications. Compr Rev Food Sci Food Saf 18(6):1859-1881. https:// doi.org/10.1111/1541-4337.12494

Loeschcke A, Thies S (2015) Pseudomonas putida-a versatile host for the production of natural products. Appl Microbiol Biotechnol 99(15): 6197-6214. https://doi.org/10.1007/s00253-015-6745-4

Loeschcke A, Markert A, Wilhelm S, Wirtz A, Rosenau F, Jaeger K-E, Drepper T (2013) TREX: a universal tool for the transfer and expression of biosynthetic pathways in bacteria. ACS Synth Biol 2(1): 22-33. https://doi.org/10.1021/sb3000657

Löwe H, Schmauder L, Hobmeier K, Kremling A, Pflüger-Grau K (2017) Metabolic engineering to expand the substrate spectrum of Pseudomonas putida toward sucrose. MicrobiologyOpen 6(4): e00473. https://doi.org/10.1002/mbo3.473

Manara A, DalCorso G, Baliardini C, Farinati S, Cecconi D, Furini A (2012) Pseudomonas putida response to cadmium: changes in membrane and cytosolic proteomes. J Proteome Res 11(8):4169-4179. https://doi.org/10.1021/pr300281f

MarketsandMarkets ${ }^{\mathrm{TM}}$ (2019) Polyhydroxyalkanoate (PHA) market by type (short chain length, medium chain length), production method (sugar fermentation, vegetable oil fermentation, methane fermentation), application, and region - global forecast to 2024. p 152

Martinelli L, Nikel PI (2019) Breaking the state-of-the-art in the chemical industry with new-to-Nature products via synthetic microbiology. Microb Biotechnol 12(2):187-190. https://doi.org/10.1111/17517915.13372

Martinez A, Kolvek SJ, Yip CLT, Hopke J, Brown KA, MacNeil IA, Osburne MS (2004) Genetically modified bacterial strains and novel bacterial artificial chromosome shuttle vectors for constructing environmental libraries and detecting heterologous natural products in multiple expression hosts. Appl Environ Microbiol 70(4):24522463. https://doi.org/10.1128/aem.70.4.2452-2463.2004

Martínez-Bueno MA, Tobes R, Rey M, Ramos J-L (2002) Detection of multiple extracytoplasmic function (ECF) sigma factors in the genome of Pseudomonas putida KT2440 and their counterparts in Pseudomonas aeruginosa PA01. Environ Microbiol 4(12):842855. https://doi.org/10.1046/j.1462-2920.2002.00371.x

Martínez-García E, de Lorenzo V (2011) Engineering multiple genomic deletions in Gram-negative bacteria: analysis of the multi-resistant antibiotic profile of Pseudomonas putida KT2440. Environ Microbiol 13(10):2702-2716. https://doi.org/10.1111/j.1462-2920. 2011.02538.x
Martinez-Garcia E, de Lorenzo V (2012) Transposon-based and plasmidbased genetic tools for editing genomes of gram-negative bacteria. Methods Mol Biol 813:267-283

Martínez-García E, de Lorenzo V (2017) Molecular tools and emerging strategies for deep genetic/genomic refactoring of Pseudomonas. Curr Opin Biotechnol 47:120-132. https://doi.org/10.1016/j. copbio.2017.06.013

Martínez-García E, Lorenzo V (2019) Pseudomonas putida in the quest of programmable chemistry. Curr Opin Biotechnol 59:111-121. https://doi.org/10.1016/j.copbio.2019.03.012

Martínez-García E, Aparicio T, de Lorenzo V, Nikel PI (2014a) New transposon tools tailored for metabolic engineering of Gramnegative microbial cell factories. Front Bioeng Biotechnol 2(46). https://doi.org/10.3389/fbioe.2014.00046

Martínez-García E, Nikel PI, Aparicio T, de Lorenzo V (2014b) Pseudomonas 2.0: genetic upgrading of $P$. putida KT2440 as an enhanced host for heterologous gene expression. Microb Cell Factories 13:159-159. https://doi.org/10.1186/s12934-014-0159-3

Martínez-García E, Aparicio T, Goñi-Moreno A, Fraile S, de Lorenzo V (2015) SEVA 2.0: an update of the Standard European Vector Architecture for de-/re-construction of bacterial functionalities. Nucleic Acids Res 43(Database issue):D1183-D1189. https://doi. org/10.1093/nar/gku1114

Martínez-García E, Goñi-Moreno A, Bartley B, McLaughlin J, SánchezSampedro L, Pascual del Pozo H, Prieto Hernández C, Marletta AS, De Lucrezia D, Sánchez-Fernández G, Fraile S, de Lorenzo V (2019) SEVA 3.0: an update of the Standard European Vector Architecture for enabling portability of genetic constructs among diverse bacterial hosts. Nucleic Acids Res 48(D1):D1164-D1170. https://doi.org/10.1093/nar/gkz1024

Martinez-Garcia E, Fraile S, Rodriguez-Espeso D, Vecchietti D, Bertoni G, de Lorenzo V (2020) The naked cell: emerging properties of a surfome-streamlined Pseudomonas putida strain. bioRxiv: 2020.05.17.100628 https://doi.org/10.1101/2020.05.17.100628

Matilla MA, Krell T (2018) Plant growth promotion and biocontrol mediated by plant-associated bacteria. In: Egamberdieva D, Ahmad P (eds) Plant microbiome: stress response. Springer Singapore, Singapore, pp 45-80

Meijnen J-P, de Winde JH, Ruijssenaars HJ (2008) Engineering Pseudomonas putida S12 for efficient utilization of d-Xylose and 1-Arabinose. Appl Environ Microbiol 74(16):5031. https://doi.org/ 10.1128/aem.00924-08

Meijnen J-P, de Winde JH, Ruijssenaars HJ (2009) Establishment of oxidative d-xylose metabolism in Pseudomonas putida S12. Appl Environ Microbiol 75(9):2784. https://doi.org/10.1128/aem.0271308

Mendonca CM, Wilkes RA, Aristilde L (2020) Advancements in ${ }^{13} \mathrm{C}$ isotope tracking of synergistic substrate co-utilization in Pseudomonas species and implications for biotechnology applications. Curr Opin Biotechnol 64:124-133. https://doi.org/10.1016/j. copbio.2020.02.004

Meyers A, Furtmann C, Gesing K, Tozakidis IEP, Jose J (2019) Cell density-dependent auto-inducible promoters for expression of recombinant proteins in Pseudomonas putida. Microb Biotechnol 12(5):1003-1013. https://doi.org/10.1111/1751-7915.13455

Mi J, Becher D, Lubuta P, Dany S, Tusch K, Schewe H, Buchhaupt M, Schrader J (2014) De novo production of the monoterpenoid geranic acid by metabolically engineered Pseudomonas putida. Microb Cell Factories 13:170-170. https://doi.org/10.1186/s12934-014-0170-8

Mi J, Schewe H, Buchhaupt M, Holtmann D, Schrader J (2016) Efficient hydroxylation of 1,8-cineole with monoterpenoid-resistant recombinant Pseudomonas putida GS1. World J Microbiol Biotechnol 32(7):112. https://doi.org/10.1007/s11274-016-2071-y

Mirata MA, Heerd D, Schrader J (2009) Integrated bioprocess for the oxidation of limonene to perillic acid with Pseudomonas putida 
DSM 12264. Process Biochem 44(7):764-771. https://doi.org/10. 1016/j.procbio.2009.03.013

Molina L, Rosa RL, Nogales J, Rojo F (2019) Pseudomonas putida KT2440 metabolism undergoes sequential modifications during exponential growth in a complete medium as compounds are gradually consumed. Environ Microbiol 21(7):2375-2390. https://doi.org/10. 1111/1462-2920.14622

Możejko-Ciesielska J, Mostek A (2019) A 2D-DIGE-based proteomic analysis brings new insights into cellular responses of Pseudomonas putida KT2440 during polyhydroxyalkanoates synthesis. Microb Cell Factories 18(1):93. https://doi.org/10.1186/ s12934-019-1146-5

Mozejko-Ciesielska J, Pokoj T, Ciesielski S (2018) Transcriptome remodeling of Pseudomonas putida KT2440 during mcl-PHAs synthesis: effect of different carbon sources and response to nitrogen stress. J Ind Microbiol Biotechnol 45(6):433-446. https://doi.org/ 10.1007/s10295-018-2042-4

Mozejko-Ciesielska J, Szacherska K, Marciniak P (2019) Pseudomonas species as producers of eco-friendly polyhydroxyalkanoates. J Polym Environ 27(6):1151-1166. https://doi.org/10.1007/s10924019-01422-1

Müller C, Petruschka L, Cuypers H, Burchhardt G, Herrmann H (1996) Carbon catabolite repression of phenol degradation in Pseudomonas putida is mediated by the inhibition of the activator protein PhlR. J Bacteriol 178(7):2030-2036. https://doi.org/10.1128/jb.178.7. 2030-2036.1996

Nakazawa T (2002) Travels of a Pseudomonas, from Japan around the world. Environ Microbiol 4(12):782-786. https://doi.org/10.1046/j. 1462-2920.2002.00310.x

National Archives and Records Administration (1982) Federal Register. $\mathrm{p}$ 17197

Nelson KE, Weinel C, Paulsen IT, Dodson RJ, Hilbert H, Martins dos Santos VAP, Fouts DE, Gill SR, Pop M, Holmes M, Brinkac L, Beanan M, DeBoy RT, Daugherty S, Kolonay J, Madupu R, Nelson W, White O, Peterson J, Khouri H, Hance I, Lee PC, Holtzapple E, Scanlan D, Tran K, Moazzez A, Utterback T, Rizzo M, Lee K, Kosack D, Moestl D, Wedler H, Lauber J, Stjepandic D, Hoheisel J, Straetz M, Heim S, Kiewitz C, Eisen J, Timmis KN, Düsterhöft A, Tümmler B, Fraser CM (2002) Complete genome sequence and comparative analysis of the metabolically versatile Pseudomonas putida KT2440. Environ Microbiol 4(12):799-808. https://doi.org/10.1046/j.1462-2920.2002.00366.x

Nieto-Domínguez M, Nikel PI (2020) Intersecting xenobiology and neometabolism to bring novel chemistries to life. ChemBioChem https://doi.org/10.1002/cbic.202000091

Nijkamp K, van Luijk N, de Bont JAM, Wery J (2005) The solventtolerant Pseudomonas putida S12 as host for the production of cinnamic acid from glucose. Appl Microbiol Biotechnol 69(2): 170-177. https://doi.org/10.1007/s00253-005-1973-7

Nikel PI, de Lorenzo V (2013a) Engineering an anaerobic metabolic regime in Pseudomonas putida KT2440 for the anoxic biodegradation of 1,3-dichloroprop-1-ene. Metab Eng 15:98-112

Nikel PI, de Lorenzo V (2013b) Implantation of unmarked regulatory and metabolic modules in Gram-negative bacteria with specialised minitransposon delivery vectors. J Biotechnol 163(2):143-154. https:// doi.org/10.1016/j.jbiotec.2012.05.002

Nikel PI, de Lorenzo V (2018) Pseudomonas putida as a functional chassis for industrial biocatalysis: From native biochemistry to transmetabolism. Metab Eng 50:142-155. https://doi.org/10.1016/j. ymben.2018.05.005

Nikel PI, Kim J, de Lorenzo V (2014) Metabolic and regulatory rearrangements underlying glycerol metabolism in Pseudomonas putida KT2440. Environ Microbiol 16(1):239-254

Nikel PI, Chavarria M, Fuhrer T, Sauer U, de Lorenzo V (2015) Pseudomonas putida KT2440 strain metabolizes glucose through a cycle formed by enzymes of the Entner-Doudoroff, Embden-
Meyerhof-Parnas, and pentose phosphate pathways. J Biol Chem 290(43):25920-25932. https://doi.org/10.1074/jbc.M1 15.687749

Nikodinovic-Runic J, Flanagan M, Hume AR, Cagney G, Connor KE (2009) Analysis of the Pseudomonas putida CA-3 proteome during growth on styrene under nitrogen-limiting and non-limiting conditions. Microbiology 155(10):3348-3361. https://doi.org/10.1099/ mic. 0.031153-0

Niu W, Willett H, Mueller J, He X, Kramer L, Ma B, Guo J (2020) Direct biosynthesis of adipic acid from lignin-derived aromatics using engineered Pseudomonas putida KT2440. Metab Eng 59:151161. https://doi.org/10.1016/j.ymben.2020.02.006

Nogales J, Palsson BO, Thiele I (2008) A genome-scale metabolic reconstruction of Pseudomonas putida KT2440: iJN746 as a cell factory. BMC Syst Biol 2(79):1752-0509

Nogales J, García JL, Díaz E (2017) Degradation of aromatic compounds in Pseudomonas: a systems biology view. In: Rojo F (ed) Aerobic utilization of hydrocarbons, oils and lipids handbook of hydrocarbon and lipid microbiology. Springer, Cham, pp 1-49

Nogales J, Mueller J, Gudmundsson S, Canalejo FJ, Duque E, Monk J, Feist AM, Ramos JL, Niu W, Palsson BO (2020) High-quality genome-scale metabolic modelling of Pseudomonas putida highlights its broad metabolic capabilities. Environ Microbiol 22(1):255-269. https://doi.org/10.1111/1462-2920.14843

Novamont S.p.A. (2019) Novamont starts construction of a demo plant for the production of furandicarboxylic acid Publisher. https://www. novamont.com/eng/read-press-release/novamont-startsconstruction-of-a-demo-plant-for-the-production-offurandicarboxylic-acid/ Accessed 20/05/20

Oberhardt M, Puchałka J, Martins dos Santos V, Papin J (2011) Reconciliation of genome-scale metabolic reconstructions for comparative systems analysis. PLoS Comput Biol 7:e1001116. https:// doi.org/10.1371/journal.pcbi.1001116

Pandit AV, Srinivasan S, Mahadevan R (2017) Redesigning metabolism based on orthogonality principles. Nat Commun 8(1):15188. https:// doi.org/10.1038/ncomms 15188

Peng J, Miao L, Chen X, Liu P (2018) Comparative transcriptome analysis of Pseudomonas putida KT2440 revealed its response mechanisms to elevated levels of zinc stress. Front Microbiol 9(1669). https://doi.org/10.3389/fmicb.2018.01669

Pham NN, Chen CY, Li H, Nguyen MTT, Nguyen PKP, Tsai SL, Chou JY, Ramli TC, Hu YC (2020) Engineering stable Pseudomonas putida S12 by CRISPR for 2,5-furandicarboxylic acid (FDCA) production. ACS Synth Biol 28(10)

Poblete-Castro I, Becker J, Dohnt K, dos Santos VM, Wittmann C (2012a) Industrial biotechnology of Pseudomonas putida and related species. Appl Microbiol Biotechnol 93(6):2279-2290. https:// doi.org/10.1007/s00253-012-3928-0

Poblete-Castro I, Escapa IF, Jäger C, Puchalka J, Chi Lam CM, Schomburg D, Prieto MA, dos Santos VAP M (2012b) The metabolic response of $P$. putida KT2442 producing high levels of polyhydroxyalkanoate under single- and multiple-nutrient-limited growth: highlights from a multi-level omics approach. Microb Cell Factories 11(1):34. https://doi.org/10.1186/1475-2859-11-34

Poblete-Castro I, Binger D, Rodrigues A, Becker J, Martins dos Santos VAP, Wittmann C (2013) In-silico-driven metabolic engineering of Pseudomonas putida for enhanced production of polyhydroxyalkanoates. Metab Eng 15:113-123. https://doi.org/10. 1016/j.ymben.2012.10.004

Poblete-Castro I, Binger D, Oehlert R, Rohde M (2014) Comparison of mcl-Poly(3-hydroxyalkanoates) synthesis by different Pseudomonas putida strains from crude glycerol: citrate accumulates at high titer under PHA-producing conditions. BMC Biotechnol 14(1):962. https://doi.org/10.1186/s12896-014-0110-z

Poblete-Castro I, Aravena-Carrasco C, Orellana-Saez M, Pacheco N, Cabrera A, Borrero-de Acuña JM (2020a) Engineering the osmotic state of Pseudomonas putida KT2440 for efficient cell disruption 
and downstream processing of poly(3-hydroxyalkanoates). Front Bioeng Biotechnol 8:161-161. https://doi.org/10.3389/fbioe.2020. 00161

Poblete-Castro I, Wittmann C, Nikel PI (2020b) Biochemistry, genetics and biotechnology of glycerol utilization in Pseudomonas species. Microb Biotechnol 13(1):32-53. https://doi.org/10.1111/17517915.13400

Poltronieri P, Kumar P (2017) Polyhydroxyalcanoates (PHAs) in industrial applications. In: Martínez LMT, Kharissova OV, Kharisov BI (eds) Handbook of ecomaterials. Springer International Publishing, Cham, pp 1-30

Prieto A, Escapa IF, Martínez V, Dinjaski N, Herencias C, de la Peña F, Tarazona N, Revelles O (2016) A holistic view of polyhydroxyalkanoate metabolism in Pseudomonas putida. Environ Microbiol 18(2):341-357. https://doi.org/10.1111/14622920.12760

Puchałka J, Oberhardt MA, Godinho M, Bielecka A, Regenhardt D, Timmis KN, Papin JA, Martins dos Santos VAP (2008) Genomescale reconstruction and analysis of the Pseudomonas putida KT2440 metabolic network facilitates applications in biotechnology. PLoS Comput Biol 4(10):e1000210. https://doi.org/10.1371/ journal.pcbi.1000210

QY Research (2020) Global 2,5-furandicarboxylic acid (FDCA) market research report 2020. p 98

Ramos J-L, Sol Cuenca M, Molina-Santiago C, Segura A, Duque E, Gómez-García MR, Udaondo Z, Roca A (2015) Mechanisms of solvent resistance mediated by interplay of cellular factors in Pseudomonas putida. FEMS Microbiol Rev 39(4):555-566. https://doi.org/10.1093/femsre/fuv006

Rehm BHA (2009) Pseudomonas applications encyclopedia of industrial biotechnology. pp 1-15

Rehm BHA, Valla S (1997) Bacterial alginates: biosynthesis and applications. Appl Microbiol Biotechnol 48(3):281-288. https://doi.org/ 10.1007/s002530051051

Salvachúa D, Johnson C, Singer C, Rohrer H, Peterson D, Black B, Knapp A, Beckham G (2018) Bioprocess development for muconic acid production from aromatic compounds and lignin. Green Chem 20. https://doi.org/10.1039/c8gc02519c

Salvachúa D, Rydzak T, Auwae R, De Capite A, Black BA, Bouvier JT, Cleveland NS, Elmore JR, Furches A, Huenemann JD, Katahira R, Michener WE, Peterson DJ, Rohrer H, Vardon DR, Beckham GT, Guss AM (2020a) Metabolic engineering of Pseudomonas putida for increased polyhydroxyalkanoate production from lignin. Microb Biotechnol 13(1):290-298. https://doi.org/10.1111/1751-7915. 13481

Salvachúa D, Werner AZ, Pardo I, Michalska M, Black BA, Donohoe BS, Haugen SJ, Katahira R, Notonier S, Ramirez KJ, Amore A, Purvine SO, Zink EM, Abraham PE, Giannone RJ, Poudel S, Laible PD, Hettich RL, Beckham GT (2020b) Outer membrane vesicles catabolize lignin-derived aromatic compounds in Pseudomonas putida KT2440. PNAS 117(17):9302-9310. https:// doi.org/10.1073/pnas.1921073117

Sanchez-Pascuala A, de Lorenzo V, Nikel PI (2017) Refactoring the Embden-Meyerhof-Parnas pathway as a whole of portable GlucoBricks for implantation of glycolytic modules in Gramnegative bacteria. ACS Synth Biol 6(5):793-805

Sánchez-Pascuala A, Fernández-Cabezón L, de Lorenzo V, Nikel PI (2019) Functional implementation of a linear glycolysis for sugar catabolism in Pseudomonas putida. Metab Eng 54:200-211. https:// doi.org/10.1016/j.ymben.2019.04.005

Sasnow SS, Wei H, Aristilde L (2016) Bypasses in intracellular glucose metabolism in iron-limited Pseudomonas putida. MicrobiologyOpen 5(1):3-20. https://doi.org/10.1002/mbo3.287

Schmitz S, Nies S, Wierckx N, Blank LM, Rosenbaum MA (2015) Engineering mediator-based electroactivity in the obligate aerobic bacterium Pseudomonas putida KT2440. Front Microbiol 6(284). https://doi.org/10.3389/fmicb.2015.00284

Schulze B, Wubbolts MG (1999) Biocatalysis for industrial production of fine chemicals. Curr Opin Biotechnol 10(6):609-615

Sharma P, Fu J, Zhang X, Fristensky B, Sparling R, Levin D (2014) Genome features of Pseudomonas putida LS46, a novel polyhydroxyalkanoate producer and its comparison with other P. putida strains. AMB Express 4. https://doi.org/10.1186/s13568014-0037-8

Shim H, Yang S-T (1999) Biodegradation of benzene, toluene, ethylbenzene, and o-xylene by a coculture of Pseudomonas putida and Pseudomonas fluorescens immobilized in a fibrous-bed bioreactor. J Biotechnol 67(2):99-112. https://doi.org/10.1016/S01681656(98)00166-7

Silby MW, Winstanley C, Godfrey SAC, Levy SB, Jackson RW (2011) Pseudomonas genomes: diverse and adaptable. FEMS Microbiol Rev 35(4):652-680. https://doi.org/10.1111/j.1574-6976.2011. 00269.x

Silva-Rocha R, Martínez-García E, Calles B, Chavarría M, Arce Rodríguez A, De las Heras A, Paez Espino D, Durante G, Kim J, Nikel PI, Platero R, Lorenzo V (2012) The Standard European Vector Architecture (SEVA): a coherent platform for the analysis and deployment of complex prokaryotic phenotypes. Nucleic Acids Res 41. https://doi.org/10.1093/nar/gks1119

Simon O, Klaiber I, Huber A, Pfannstiel J (2014) Comprehensive proteome analysis of the response of Pseudomonas putida KT2440 to the flavor compound vanillin. J Proteome 109:212-227. https://doi.org/ 10.1016/j.jprot.2014.07.006

Simon O, Klebensberger J, Mükschel B, Klaiber I, Graf N, Altenbuchner J, Huber A, Hauer B, Pfannstiel J (2015) Analysis of the molecular response of Pseudomonas putida KT2440 to the next-generation biofuel n-butanol. J Proteome 122:11-25. https://doi.org/10.1016/j. jprot.2015.03.022

Sohn SB, Kim TY, Park JM, Lee SY (2010) In silico genome-scale metabolic analysis of Pseudomonas putida KT2440 for polyhydroxyalkanoate synthesis, degradation of aromatics and anaerobic survival. Biotechnol J 5(7):739-750

Sonoki T, Takahashi K, Sugita H, Hatamura M, Azuma Y, Sato T, Suzuki S, Kamimura N, Masai E (2018) Glucose-free cis,cis-muconic acid production via new metabolic designs corresponding to the heterogeneity of lignin. ACS Sustain Chem Eng 6(1):1256-1264. https:// doi.org/10.1021/acssuschemeng.7b03597

Sousa AF, Vilela C, Fonseca AC, Matos M, Freire CSR, Gruter G-JM, Coelho JFJ, Silvestre AJD (2015) Biobased polyesters and other polymers from 2,5-furandicarboxylic acid: a tribute to furan excellency. Polym Chem 6(33):5961-5983. https://doi.org/10.1039/ c5py00686d

Steen A, Utkur FO, Borrero-de Acuna JM, Bunk B, Roselius L, Buhler B, Jahn D, Schobert M (2013) Construction and characterization of nitrate and nitrite respiring Pseudomonas putida KT2440 strains for anoxic biotechnical applications. J Biotechnol 163(2):155-165

Stephan S, Heinzle E, Wenzel S, Krug D, Müller R, Wittmann C (2006) Metabolic physiology of Pseudomonas putida for heterologous production of myxochromide. Process Biochem 41:2146-2152. https:// doi.org/10.1016/j.procbio.2006.06.022

Stora Enso (2019) Stora Enso invests in pilot plant for bio-based plastic packaging material. Publisher. https:/www.storaenso.com/en/ newsroom/regulatory-and-investor-releases/2019/12/stora-ensoinvests-in-pilot-plant-for-bio-based-plastic-packaging-material Accessed 20 May 2020

Sudarsan S, Dethlefsen S, Blank LM, Siemann-Herzberg M, Schmid A (2014) The functional structure of central carbon metabolism in Pseudomonas putida KT2440. Appl Environ Microbiol 80(17): 5292-5303. https://doi.org/10.1128/aem.01643-14

Thompson M, Valencia L, Blake-Hedges J, Cruz-Morales P, Velasquez A, Pearson A, Sermeno L, Sharpless W, Benites V, Chen Y, Baidoo 
EK, Petzold C, Deutschbauer A, Keasling J (2019) Omics-driven identification and elimination of valerolactam catabolism in Pseudomonas putida KT2440 for increased product titer. Metab Eng Commun 9:e00098. https://doi.org/10.1016/j.mec.2019. e00098

Thum O, Engel P, Gehring C, Schaffer S, Wessel M (2017) Methods of producing rhamnolipids. United States Patent 20170096695A1,

Timmis KN (2002) Pseudomonas putida: a cosmopolitan opportunist par excellence. Environ Microbiol 4(12):779-781. https://doi.org/10. 1046/j.1462-2920.2002.00365.x

Tiso T, Wierckx N, Blank L (2014) Non-pathogenic Pseudomonas as platform for industrial biocatalysis. In: Grunwald P (ed) Industrial biocatalysis, vol 1. CRC Press, Boca Raton, pp 323-372

Tiso T, Zauter R, Tulke H, Leuchtle B, Li W-J, Behrens B, Wittgens A, Rosenau F, Hayen H, Blank LM (2017) Designer rhamnolipids by reduction of congener diversity: production and characterization. Microb Cell Factories 16(1):225-225. https://doi.org/10.1186/ s12934-017-0838-y

Tozakidis IEP, Lüken LM, Üffing A, Meyers A, Jose J (2020) Improving the autotransporter-based surface display of enzymes in Pseudomonas putida KT2440. Microb Biotechnol 13(1):176-184. https://doi.org/10.1111/1751-7915.13419

Tripathi L, Wu L-P, Dechuan M, Chen J, Wu Q, Chen G-Q (2013) Pseudomonas putida KT2442 as a platform for the biosynthesis of polyhydroxyalkanoates with adjustable monomer contents and compositions. Bioresour Technol 142:225-231. https://doi.org/10.1016/ j.biortech.2013.05.027

Udaondo Z, Duque E, Fernández M, Molina L, Jdl T, Bernal P, Niqui J-L, Pini C, Roca A, Matilla MA, Antonia Molina-Henares M, SilvaJiménez H, Navarro-Avilés G, Busch A, Lacal J, Krell T, Segura A, Ramos J-L (2012) Analysis of solvent tolerance in Pseudomonas putida DOT-T1E based on its genome sequence and a collection of mutants. FEBS Lett 586(18):2932-2938. https://doi.org/10.1016/j. febslet.2012.07.031

Udaondo Z, Molina L, Segura A, Duque E, Ramos JL (2016) Analysis of the core genome and pangenome of Pseudomonas putida. Environ Microbiol 18(10):3268-3283

Udiković-Kolić N, Scott C, Martin-Laurent F (2012) Evolution of atrazine-degrading capabilities in the environment. Appl Microbiol Biotechnol 96(5):1175-1189. https://doi.org/10.1007/s00253-0124495-0

Valentine ME, Kirby BD, Withers TR, Johnson SL, Long TE, Hao Y, Lam JS, Niles RM, Yu HD (2020) Generation of a highly attenuated strain of Pseudomonas aeruginosa for commercial production of alginate. Microb Biotechnol 13(1):162-175. https://doi.org/10. 1111/1751-7915.13411

Vallon T, Simon O, Rendgen-Heugle B, Frana S, Mückschel B, Broicher A, Siemann-Herzberg M, Pfannenstiel J, Hauer B, Huber A, Breuer M, Takors R (2015) Applying systems biology tools to study nbutanol degradation in Pseudomonas putida KT2440. Eng Life Sci 15(8):760-771. https://doi.org/10.1002/elsc.201400051

van Beilen JB, Holtackers R, Lüscher D, Bauer U, Witholt B, Duetz WA (2005) Biocatalytic production of perillyl alcohol from limonene by using a novel Mycobacterium sp. cytochrome P450 alkane hydroxylase expressed in Pseudomonas putida. Appl Environ Microbiol 71(4):1737-1744. https://doi.org/10.1128/aem.71.4.1737-1744. 2005

van Duuren JBJH, Wijte D, Leprince A, Karge B, Puchalka J, Wery J, Dos Santos VA, Eggink G, Mars AE (2011) Generation of a catR deficient mutant of $P$. putida KT2440 that produces cis, cismuconate from benzoate at high rate and yield. J Biotechnol 156(3):163-172. https://doi.org/10.1016/j.jbiotec.2011.08.030

van Duuren JBJH, Wijte D, Karge B, dos Santos VA, Yang Y, Mars AE, Eggink G (2012) pH-stat fed-batch process to enhance the production of cis, cis-muconate from benzoate by Pseudomonas putida
KT2440-JD1. Biotechnol Prog 28(1):85-92. https://doi.org/10. 1002/btpr.709

van Duuren JBJH, de Wild PJ, Starck S, Bradtmöller C, Selzer M, Mehlmann K, Schneider R, Kohlstedt M, Poblete-Castro I, Stolzenberger J, Barton N, Fritz M, Scholl S, Venus J, Wittmann C (2020) Limited life cycle and cost assessment for the bioconversion of lignin-derived aromatics into adipic acid. Biotechnol Bioeng 117(5):1381-1393. https://doi.org/10.1002/bit.27299

Vardon DR, Franden MA, Johnson CW, Karp EM, Guarnieri MT, Linger JG, Salm MJ, Strathmann TJ, Beckham GT (2015) Adipic acid production from lignin. Energy Environ Sci 8(2):617-628. https:// doi.org/10.1039/c4ee03230f

Vardon DR, Rorrer NA, Salvachúa D, Settle AE, Johnson CW, Menart MJ, Cleveland NS, Ciesielski PN, Steirer KX, Dorgan JR, Beckham GT (2016) cis,cis-Muconic acid: separation and catalysis to bioadipic acid for nylon-6,6 polymerization. Green Chem 18(11): 3397-3413. https://doi.org/10.1039/c5gc02844b

Verhoef S, Wierckx N, Westerhof RGM, de Winde JH, Ruijssenaars HJ (2009) Bioproduction of p-hydroxystyrene from glucose by the solvent-tolerant bacterium Pseudomonas putida S12 in a twophase water-decanol fermentation. Appl Environ Microbiol 75(4): 931-936. https://doi.org/10.1128/aem.02186-08

Volke DC, Nikel PI (2018) Getting bacteria in shape: synthetic morphology approaches for the design of efficient microbial cell factories. Adv Biosyst 2(11):1800111. https://doi.org/10.1002/adbi. 201800111

Volke DC, Friis L, Wirth NT, Turlin J, Nikel PI (2020a) Synthetic control of plasmid replication enables target- and self-curing of vectors and expedites genome engineering of Pseudomonas putida. Metab Eng Commun 10:e0126

Volke DC, Turlin J, Mol V, Nikel PI (2020b) Physical decoupling of $\mathrm{XylS} / \mathrm{Pm}$ regulatory elements and conditional proteolysis enable precise control of gene expression in Pseudomonas putida. Microb Biotechnol 13(1):222-232. https://doi.org/10.1111/1751-7915. 13383

Wang H-H, Zhou X-R, Liu Q, Chen G-Q (2010) Biosynthesis of polyhydroxyalkanoate homopolymers by Pseudomonas putida. Appl Microbiol Biotechnol 89:1497-1507. https://doi.org/10.1007/ s00253-010-2964-X

Wang J, Liu X, Jia Z, Sun L, Zhu J (2018) Highly crystalline polyesters synthesized from furandicarboxylic acid (FDCA): potential biobased engineering plastic. Eur Polym J 109:379-390. https://doi. org/10.1016/j.eurpolymj.2018.10.014

Wehrs M, Tanjore D, Eng T, Lievense J, Pray TR, Mukhopadhyay A (2019) Engineering robust production microbes for large-scale cultivation. Trends Biotechnol 27(6):524-537. https://doi.org/10.1016/ j.tim.2019.01.006

Wierckx NJP, Ballerstedt H, de Bont JAM, Wery J (2005) Engineering of solvent-tolerant Pseudomonas putida S12 for bioproduction of phenol from glucose. Appl Environ Microbiol 71(12):8221-8227. https://doi.org/10.1128/aem.71.12.8221-8227.2005

Wierckx NJP, Elink Schuurman TD, Kuijper SM, Ruijssenaars HJ (2012) Genetically modified cell and process for use of said cell. WO2012064195

Wijte D, van Baar BLM, Heck AJR, Altelaar AFM (2011) Probing the proteome response to toluene exposure in the solvent tolerant Pseudomonas putida S12. J Proteome Res 10(2):394-403. https:// doi.org/10.1021/pr100401n

Wirth NT, Kozaeva E, Nikel PI (2020) Accelerated genome engineering of Pseudomonas putida by I-SceI-mediated recombination and CRISPR-Cas9 counterselection. Microb Biotechnol 13(1):233249. https://doi.org/10.1111/1751-7915.13396

Wittgens A, Tiso T, Arndt TT, Wenk P, Hemmerich J, Muller C, Wichmann R, Kupper B, Zwick M, Wilhelm S, Hausmann R, Syldatk C, Rosenau F, Blank LM (2011) Growth independent rhamnolipid production from glucose using the non-pathogenic 
Pseudomonas putida KT2440. Microb Cell Factories 10(80):14752859

Wittgens A, Santiago-Schuebel B, Henkel M, Tiso T, Blank LM, Hausmann R, Hofmann D, Wilhelm S, Jaeger K-E, Rosenau F (2018) Heterologous production of long-chain rhamnolipids from Burkholderia glumae in Pseudomonas putida - a step forward to tailor-made rhamnolipids. Appl Microbiol Biotechnol 102(3): 1229-1239. https://doi.org/10.1007/s00253-017-8702-x

Yu J-L, Xia X-X, Zhong J-J, Qian Z-G (2014) Direct biosynthesis of adipic acid from a synthetic pathway in recombinant Escherichia coli. Biotechnol Bioeng 111(12):2580-2586. https://doi.org/10. 1002/bit. 25293

Yu S, Plan MR, Winter G, Krömer JO (2016) Metabolic Engineering of Pseudomonas putida KT2440 for the Production of para-Hydroxy Benzoic Acid. Front Bioeng Biotechnol 4(90). https://doi.org/10. 3389/fbioe.2016.00090

Yu S, Lai B, Plan MR, Hodson MP, Lestari EA, Song H, Kromer JO (2018) Improved performance of Pseudomonas putida in a bioelectrochemical system through overexpression of periplasmic glucose dehydrogenase. Biotechnol Bioeng 115(1):145-155

Yuan Q, Huang T, Li P, Hao T, Li F, Ma H, Wang Z, Zhao X, Chen T, Goryanin I (2017) Pathway-consensus approach to metabolic network reconstruction for Pseudomonas putida KT2440 by systematic comparison of published models. PLoS One 12(1):e0169437. https://doi.org/10.1371/journal.pone.0169437

Yuan H, Liu H, Du J, Liu K, Wang T, Liu L (2020) Biocatalytic production of 2,5-furandicarboxylic acid: recent advances and future perspectives. Appl Microbiol Biotechnol 104(2):527-543. https://doi. org/10.1007/s00253-019-10272-9

Zhao M, Huang D, Zhang X, Koffas MAG, Zhou J, Deng Y (2018) Metabolic engineering of Escherichia coli for producing adipic acid through the reverse adipate-degradation pathway. Metab Eng 47: 254-262. https://doi.org/10.1016/j.ymben.2018.04.002

Zhou Y, Lin L, Wang H, Zhang Z, Zhou J, Jiao N (2020) Development of a CRISPR/Cas9n-based tool for metabolic engineering of Pseudomonas putida for ferulic acid-to-polyhydroxyalkanoate bioconversion. Commun Biol 3(1):98. https://doi.org/10.1038/s42003020-0824-5

Zobel S, Benedetti I, Eisenbach L, de Lorenzo V, Wierckx N, Blank LM (2015) Tn7-based device for calibrated heterologous gene expression in Pseudomonas putida. ACS Synth Biol 4(12):1341-1351. https://doi.org/10.1021/acssynbio.5b00058

Publisher's note Springer Nature remains neutral with regard to jurisdictional claims in published maps and institutional affiliations. 